UNIVERSIDADE DE SÃO PAULO

FACULDADE DE FILOSOFIA, CIÊNCIAS E LETRAS DE RIBEIRÃO PRETO DEPARTAMENTO DE COMPUTAÇÃO E MATEMÁTICA

\title{
Computational modeling of the effects of transcranial magnetic stimulation on cortical neurons
}

Modelagem computacional dos efeitos da estimulação magnética transcraniana sobre neurônios corticais

VITOR VALSICHI CUZIOL

Dissertação apresentada à Faculdade de Filosofia, Ciências e Letras de Ribeirão Preto (FFCLRP) da Universidade de São Paulo (USP), como parte das exigências para a obtenção do título de Mestre em Ciências.

Área de Concentração: Computação Aplicada.

Ribeirão Preto-SP 

VITOR VALSICHI CUZIOL

Computational modeling of the effects of transcranial magnetic stimulation on cortical neurons

\title{
Modelagem computacional dos efeitos da estimulação magnética transcraniana sobre neurônios corticais
}

\author{
Versão Revisada \\ Versão original encontra-se na FFCLRP/USP.
}

Dissertação apresentada à Faculdade de Filosofia, Ciências e Letras de Ribeirão Preto (FFCLRP) da Universidade de São Paulo (USP), como parte das exigências para a obtenção do título de Mestre em Ciências.

Área de Concentração: Computação Aplicada.

Orientador: Luiz Otavio Murta Junior

Ribeirão Preto-SP 
Vitor Valsichi Cuziol

Computational modeling of the effects of transcranial magnetic stimulation on cortical neurons. Ribeirão Preto-SP, 2020.

83p. : 26 il.; $30 \mathrm{~cm}$.

Dissertação apresentada à Faculdade de Filosofia, Ciências e Letras de Ribeirão Preto da USP, como parte das exigências para a obtenção do título de Mestre em Ciências,

Área: Computação Aplicada.

Supervisor: Luiz Otavio Murta Junior

Versão corrigida.

1. Estimulação magnética transcraniana. 2. Neuroestimulação. 3. Neurociência computacional. 
Vitor Valsichi Cuziol

\section{Computational modeling of the effects of transcranial magnetic stimulation on cortical neurons}

Trabalho aprovado. Ribeirão Preto-SP, 24 de abril de 2020:

\begin{tabular}{c}
\hline $\begin{array}{c}\text { Luiz Otavio Murta Junior } \\
\text { Orientador }\end{array}$ \\
\hline Professor \\
Convidado 1 \\
\\
\hline Professor \\
Convidado 2 \\
Ribeirão Preto-SP \\
2020
\end{tabular}





\section{Acknowledgements}

I would like to thank my supervisor, Professor Luiz Otavio Murta Junior, for his helpful guidance and discussions, and for conceding computational resources indispensable to the execution of this project.

I would like to thank CAPES - Coordenação de Aperfeicoamento de Pessoal de Nível Superior - for financial support during my years of study and research.

I would also like to thank all my professors at Universidade de São Paulo for sharing their valuable knowledge, and all members of the CSIM laboratory and other colleagues who helped me and gave useful advices during the elaboration of this project. 

"The principles of magnetic stimulation are not complex. The complexity and the mystery are in the organization of the nervous system." 



\section{Abstract}

Transcranial magnetic stimulation (TMS) is a noninvasive technique of brain stimulation that has been widely used in both cognitive function studies and clinical applications. However, the biophysical mechanisms by which TMS activates cortical neurons and networks are still poorly understood. The present work aimed to create a computational model of the neuronal effects of single-pulse TMS combining compartmental models of neurons and a subject-specific electric field solution. The model consists of neurons of cortical layers L2/3 and L5, transformed to conform to cortical curvature and subjected to extracellular quasipotentials following a monophasic current waveform. First, excitation thresholds and sites of action potential initiation are determined through simulation of membrane dynamics with neurons being synaptically isolated, then epidural response is simulated by connecting them in a feedforward network. Excitation occured at morphological discontinuities such as axon terminals, and thresholds were mostly correlated with total electric field magnitude instead of the component normal to cortex. Coil orientations perpendicular to central sulcus presented lowest thresholds, with L5 neurons, in general, being more easily excitable than L2/3. The simulated epidural response of the network presented amplitude and duration in accord with experimental recordings, supporting the hypothesis of transsynaptic activation, with the time of propagation of action potentials in L2/3 axonal arbors suggesting a role in latency of I1-waves. By incorporating neuroanatomical factors to a neuronal network, the current model offers a computational framework for exploring TMS parameters and advancing the personalized use of neurostimulation.

Keywords: transcranial magnetic stimulation. neurostimulation. computational model. neuronal activation. computational neuroscience. 



\section{Resumo}

Estimulação magnética transcraniana (TMS) é uma técnica não invasiva de estimulação cerebral que é amplamente usada em estudos de funções cognitivas e aplicações clínicas. No entanto, os mecanismos biofísicos pelos quais a TMS ativa neurônios e redes corticais ainda são pouco compreendidos. O presente trabalho teve como objetivo criar um modelo computacional dos efeitos neuronais da TMS de pulso único, combinando modelos compartimentais de neurônios e solução de campo elétrico em anatomia individual. O modelo consiste de neurônios das camadas L2/3 e L5, transformados conforme a curvatura cortical e submetidos a quase-potencias extracelulares que seguem um pulso de onda monofásico. Primeiro, limiares de excitação e locais de início do potencial de ação são determinados por meio da simulação da dinâmica de membrana com neurônios sinapticamente isolados, e então a resposta epidural é simulada ao conectá-los em uma rede em alimentação direta. A excitação ocorreu em descontinuidades morfológicas como terminais axonais, e limiares estavam no geral correlacionados com a magnitude do campo elétrico total, ao invés do componente normal ao córtex. Orientações de bobina perpendiculares ao sulco central apresentaram menores limiares, com neurônios da L5, em geral, sendo mais facilmente excitados do que os da L2/3. A resposta epidural simulada pela rede apresentou amplitude e duração em acordo com o medidas experimentais, suportando a hipótese de ativação transsináptica, com o tempo de propagação de potenciais de ação em árvores axonais da L2/3 sugerindo um papel na latência de ondas I1. Ao incorporar fatores neuroanatômicos a uma rede neuronal, o presente modelo oferece um arcabouço computacional para explorar parâmetros da TMS e avançar o uso personalizado de neuroestimulação.

Palavras-chave: estimulação magnética transcraniana. neuroestimulação. modelo computacional. ativação neuronal. neurociência computacional. 



\section{List of figures}

Figure 1 - Illustration of the folding of the cortical surface, showing the position of gyri and sulci along the folds. . . . . . . . . . . . . . . . 32

Figure 2 - Illustration of a lateral view of the human brain, indicating the brain lobes and the main gyri and sulci. Modified from (BLAUSEN, 2014). . 32

Figure 3 - Illustration of a multipolar neuron with myelinated axon, indicating its main structures. Modified from (BETTS et al., 2013). . . . . . . . . . 34

Figure 4 - Most common coil current waveforms in TMS: monophasic and biphasic. Adapted from Wasserman et al. 2008 (WASSERMAN; EPSTEIN; ZIEMANN, 2008)

Figure 5 - Illustration of the main mechanisms of activation of long axons by an external electric field. Depolarization of the membrane of the axon is indicated ( $\mathrm{D}$ for depolarization, and $\mathrm{H}$ for hyperpolarization) for a given eletric field orientation (arrows). (A) Uniform electric field, causing no polarization with respect to resting axon. (B) Varying electric field (i.e., gradient), causing regions of depolarization. (C) Uniform electric field with bent axon, causing depolarization. Adapted from (HALLETT; CHOKROVERTY, 2005).

Figure 6 - Visualization of the L2/3 model neuron's morphology. (A) Morphology color-coded according to type of morphological structure: soma (black), axon (blue), apical dendrites (purple), or basal dendrites (red). Crop of region around soma (black circle), showing apical and basal dendrites. (C) Dendrogram of the morphology, indicating length of segments in vertical axis. Diameters have been scaled by a factor of 3 for visibility.

Figure 7 - Example of estimative of electric field induced by the coil (i.e., dA/dt) in different MRI-segmented subject meshes, calculated in SimNIBS. (A) $\mathrm{dA} / \mathrm{dt}$ in scalp mesh. (B) $\mathrm{dA} / \mathrm{dt}$ in grey matter mesh. Yellow sphere indicates coil position (at $4 \mathrm{~mm}$ from skin), with red and green axes indicating the coil plane (with green axis being along the coil handle) and blue axis being orthogonal to that plane. (C) Illustration of axes convention followed by SimNIBS, with $\mathrm{x}, \mathrm{y}, \mathrm{z}$ axes being indicated in A and B by the red, green, and blue axes, respectively. C: adapted from SimNIBS 2.1.2 documentation. 
Figure 8 - Pseudocolor visualization of the values of electric field magnitude in a gray matter mesh at the standard stimulation intensity (i.e., $1.0 \mathrm{~A} / \mathrm{mi}$ croseconds), calculated using the SimNIBS software package. Colors indicate values of magnitude of total electric field $(\mathrm{V} / \mathrm{m})$, according to the color bar. Red points at hand knob indicate centers of mesh elements of the motor cortex region, selected for positioning neurons. . 51

Figure 9 - Current $I(t)$ (left) used in the model as a simulation of a monophasic current passing through a TMS coil; and its time derivative $\frac{d I}{d t}$ (right) which corresponds to the normalized time course of the coil-generated electric field. . . . . . . . . . . . . . . . . . . . . 52

Figure 10 - Example of quasipotentials calculated for a L2/3 neuron by numerical integration of the electric field under quasistatic approximation. The represented neuron morphology is composed of points representing the position of each compartment of the neuron. The points are color-coded by magnitude of the quasipotential, given in $\mathrm{mV}$.

Figure 11 - Coil orientations (with coil positioned over the motor cortex) used for calculating estimates of electric field and, subsequently, excitation thresholds. Different angles of visualization are shown. Arrows in green show each coil handle orientation. Blue arrow is normal to the coil plane. (A) Anteroposterior view of gray matter mesh. (B) Topdown view of coil orientations with respect to gray matter mesh. The pseudocolor visualization in the gray matter mesh is related only to height in $\mathrm{z}$ axis (representing neither electric field nor potential) and was used only for visibility. . . . . . . . . . . . . . . . . . 55

Figure 12 - Example of 2D matrix (visualized in pseudocolor) representing the time course of the membrane potential at all compartments of a single neuron. Red arrow indicates compartment considered as action potential initiation site. Horizontal axis indicates simulation time steps (each with $0.025 \mathrm{~ms}$ ). Vertical axis indicates the indices of the compartments of the neuron. . . . . . . . . . . . . . . . . 56 56

Figure 13 - Time course of membrane potential at axon initial segment of L5 neuron with modified biophysics. A current of $19 \mathrm{nA}$ was injected at cell body during the interval of 50 and $100 \mathrm{~ms}$. Between intervals 0 to $50 \mathrm{~ms}$, and 100 to $150 \mathrm{~ms}$, no stimulus was applied. In the stimulus period of $50 \mathrm{~ms}$, the cell achieved 32 action potentials ( 0.64 per ms, or 640 per second). The modified cell, therefore, was capable of achieving I-wave frequencies (around $600 \mathrm{~Hz}$ ). Horizontal axis indicates time, in ms. Vertical axis indicates membrane potential, in $\mathrm{mV}$. . . . . . . 58 
Figure 14 - Example histogram classifying action potential initiation sites by morphological structure of the neuron (i.e., soma, apical dendrites, basal dendrites, or axonal arbor). Sites of action potential initiation (i.e., the first compartments of the neuron to cross $0 \mathrm{mV}$ after the TMS pulse) were, unanimously, axonal compartments. Compartments belonging to different neuronal structures are labeled 'node', 'myelin' (myelinated parts of axon), 'soma', 'axon' (axon initial segment), 'unmyelin' (unmyelinated parts of axon), 'apic' (apical dendrites), and 'dend' (basal dendrites). . . . . . . . . . . . . . . . . . . .

Figure 15 - Examples of time courses of membrane potential at two different compartments of a L5 neuron: soma and axon terminal. In this example, the axonal terminal was an action potential initiation site. Vertical red line indicates time of application of TMS pulse (i.e., $1.0 \mathrm{~ms}$ ) . . . . . . .

Figure 16 - Example of sites of action potential initiation across all L2/3 neurons of a population, for a single coil orientation. The neuron morphology is drawn in white, and each colored point indicates the position of a compartment where an action potential initiated, across all neurons of the population. The points are color-coded (from light blue to red) by number of neurons in the population for which an action potential initiated at that compartment. . . . . . . . . . . . . . .

Figure 17 - Direction of an universally uniform electric field (i.e., equal across all neurons, for test purposes) with respect to the stimulated sections. This figure shows a group of neurons in a cross section of the motor cortex mesh. Each red arrow (or vector) points from the soma center to the centroid of 3D points which composed the section where the first action potential initiated (after TMS pulse). The magenta arrow in the middle of the figure represents the uniform electric field vector applied to all neurons. Arrow sizes were normalized for visibility. . . .

Figure 18 - Histogram of excitation thresholds for L2/3 neurons across all coil orientations. Excitation thresholds follow a log-normal distribution. . .

Figure 19 - Scatter plot showing correlation between total electric field magnitude (i.e., considering electric field components both perpendicular and parallel to cortical surface) and excitation thresholds for L2/3 neurons at coil angle $0^{\circ}$. This tendency of high inverse correlation was kept across cell types and orientations, with the Pearson correlation coefficient ranging from -0.68 to -0.77 . . . . . . . . . . . . . . .

Figure 20 - Scatter plot showing correlation between magnitude of electric field component orthogonal (or normal) to cortical surface and excitation thresholds for L2/3 neurons at coil angle $0^{\circ}$. 
Figure 21 - Variation of means of excitation thresholds according to coil orientation. 68

Figure 22 - Simulated epidural recording, showing oscillations (I-waves) after a single pulse of TMS (with intensity $400 \mathrm{~A} / \mu$ s and at coil orientation $180^{\circ}$ ) over the feedforward network under influence of background activity (i.e., Poisson spikes). TMS pulse was applied at $55 \mathrm{~ms}$ (indicated by red vertical line). Note that pulse was applied while the signal was rising due to ongoing rhythms on L5 neurons. Top-right corner: Real epidural response to TMS pulse of human motor cortex; adapted from Lazzaro et al. 1998 (LAZZARO et al., 1998) (RUSU et al., 2014). . . 70

Figure 23 - Example of output of axon of a L5 neuron, at coil orientation $180^{\circ}$. Vertical axis indicates membrane potential $(\mathrm{mV})$; horizontal axis indicates time steps (with 100 time steps being $2.5 \mathrm{~ms}$ ). Vertical red line indicates time of $400 \mathrm{~A} / \mu \mathrm{s}$ TMS pulse (at $1.875 \mathrm{~ms}$ ). Note the 4 spikes (i.e., action potentials) after the pulse, with the fourth having larger latency, followed by approximately $6.25 \mathrm{~ms}$ of no activity. . . . . . . . 70

Figure 24 - Output of network with no Poisson spike trains over L2/3 neurons. $400 \mathrm{~A} / \mu \mathrm{s}, 180^{\circ} \mathrm{TMS}$ pulse is applied $5 \mathrm{~ms}$ after beginning of simulation, with neurons assumed to be at rest. (A) Raster plot showing spikes of the 150 neurons; L5 neuron corresponds to the topmost group of spikes, with 6 spikes for the shown time period. Shown spikes correspond to axon activation, and not soma activation; for L5 neurons, they show activation of axon initial segment, and for L23 neurons, activation of the axon terminal that projects to L5 neuron. Horizontal axis indicates time, ranging from $0 \mathrm{~ms}$ to $10 \mathrm{~ms}$; vertical axis indicates neuron index in the network. (B) Membrane potential matrix for one L2/3 neuron, visualized in pseudocolor (color bar ranging from dark blue to yellow). Vertical axis indicates each compartment, with number being its index (axonal compartments have indices ranging from near 400 to 1395); horizontal axis indicates time (in $\mathrm{ms}) . \ldots . \ldots 71$

Figure 25 - Membrane potential matrix for L5 neuron in network with no Poisson spike trains over L2/3 neurons (same simulation as Figure 24). Horizontal axis indicates time (in ms); vertical axis indicates compartments of the neuron, with number being index. Crop shows membrane potential at dendritic compartments; note the depolarization sustained along time in many compartments. . . . . . . . . . . . . . . 72 
Figure 26 - Simulated epidural response for two different coil orientations: $0^{\circ}$ (perpendicular to central sulcus, PA direction) and $180^{\circ}$. Intensity of TMS pulse was $400 \mathrm{~A} / \mu$ s for both directions, with the network being assumed as being initially at rest and under no influence of background activity throughout the simulation. . . . . . . . . . . . . . . . 72 



\section{List of tables}

Table 1 - Values of time constants, reversal potential and peak conductivity used for each simulated synaptic receptor type. . . . . . . . . . . . . 57

Table 2 - Pearson coefficient for correlation between magnitudes of different electric field components and excitation thresholds of each cell type and each coil orientation. All p-values were smaller than $1 \cdot 10^{-10} \ldots$. . . . 66

Table 3 - Means and standard deviations of the logarithm of excitation thresholds, across all coil orientations; and results of independent sample t-test performed between L2/3 and L5 thresholds. . . . . . . . . . . . . . 68 



\section{List of abbreviations and acronyms}

AMPA $\quad \alpha$-amino-3-hydroxy-5-methyl-4-isoxazolepropionic acid

\begin{tabular}{|c|c|}
\hline $\mathrm{AP}$ & Anterior-posterior \\
\hline $\mathrm{CSF}$ & Cerebrospinal fluid \\
\hline CSP & Cortical silent period \\
\hline DTI & Diffusion tensor imaging \\
\hline EEG & Electroencephalography \\
\hline EMG & Electromyography \\
\hline FEM & Finite element method \\
\hline GABA & gamma-aminobutyric acid \\
\hline GM & Gray matter \\
\hline GUI & Graphical user interface \\
\hline $\mathrm{L} 2 / 3$ & Cortical layer $2 / 3$ \\
\hline $\mathrm{L} 5$ & Cortical layer 5 \\
\hline M1 & Primary motor cortex \\
\hline MEP & Motor evoked potential \\
\hline MRI & Magnetic resonance imaging \\
\hline MT & Motor threshold \\
\hline NIBS & Non-invasive brain stimulation \\
\hline NMDA & N-Methyl-D-aspartic acid \\
\hline PA & Posterior-anterior \\
\hline $\mathrm{PDE}$ & Partial differential equation \\
\hline ODE & Ordinary differential equation \\
\hline PM & Premotor cortex \\
\hline RLC & Resistor-inductor-capacitor (electrical circuit) \\
\hline $\mathrm{RMT}$ & Resting motor threshold \\
\hline
\end{tabular}


SMA Supplementary motor area

TES Transcranial electrical stimulation

tDCS Transcranial direct-current stimulation

TMS Transcranial magnetic stimulation

VTK Visualization Toolkit (software)

WM White matter 


\section{List of symbols}

$\begin{array}{ll}\text { A } & \text { Ampère (unit of electric current) } \\ \mathrm{E} & \text { Electric field } \\ \mathrm{I} & \text { Electric current } \\ \mathrm{J} & \text { Current density } \\ \mathrm{mV} & \text { Millivolt (unit of electric potential) } \\ \psi & \text { Electric quasipotential } \\ \mathrm{V} & \text { Volt (unit of electric potential) }\end{array}$





\section{Summary}

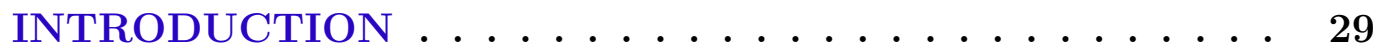

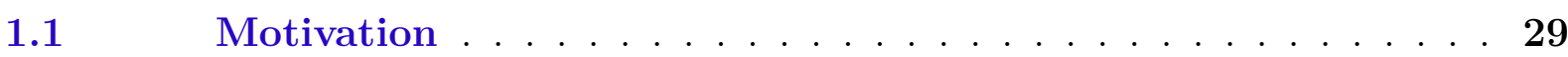

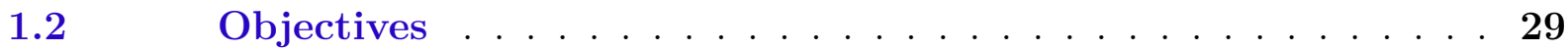

2 BACKGROUND ................. 31

2.1 The human nervous system $\ldots \ldots \ldots \ldots \ldots$

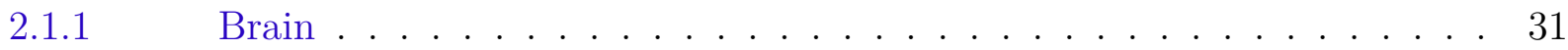

$2.1 .2 \quad$ Neurons . . . . . . . . . . . . . . . . . . . 33

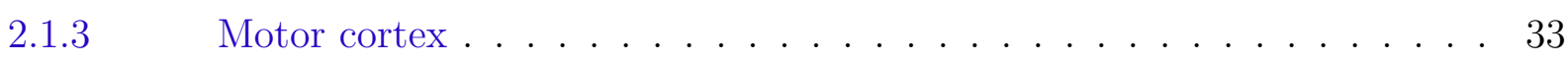

$2.2 \quad$ Transcranial magnetic stimulation . . . . . . . . . . 34

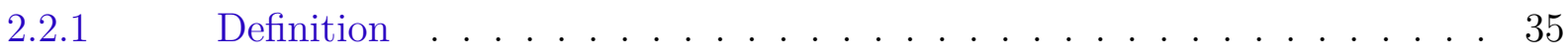

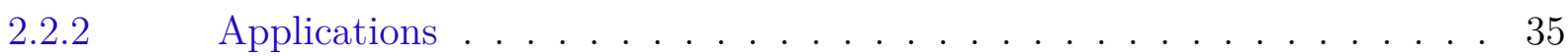

2.2 .2 .1 TMS for functional mapping $\ldots \ldots \ldots \ldots \ldots \ldots$

2.2 .2 .2 TMS for studying cortical excitability $\ldots \ldots \ldots \ldots \ldots$

$2.2 .3 \quad$ Basic physics of TMS . . . . . . . . . . . . . 37

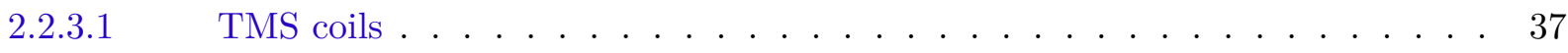

$2.2 .3 .2 \quad$ Current waveforms $\ldots \ldots \ldots \ldots \ldots \ldots \ldots \ldots$

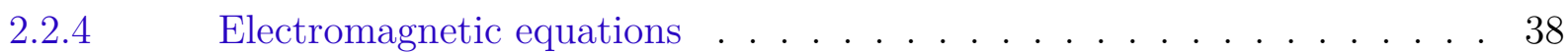

2.2.5 Calculation of the electric field induced in the brain . . . . . . . . 39

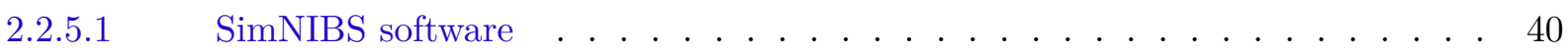

$2.3 \quad$ Modeling of neuronal membrane dynamics . . . . . . . . . . 40

2.3.1 Basic neuronal modeling . . . . . . . . . . . . . . . . . 41

2.3.2 Neuronal effects of stimulation . . . . . . . . . . . . . . . . 42

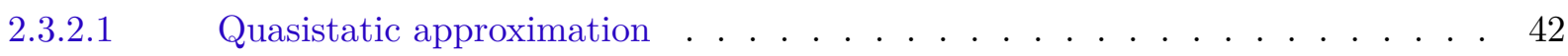

2.3.2.2 Modeling extracellular fields . . . . . . . . . . . . . . 43

2.3.3 Neuronal effects of TMS . . . . . . . . . . . . . . . . . 44

2.3.3.1 Unanswered questions on the TMS mechanism of activation . . . . . . . . 44

2.3.3.2 Computational models of TMS effects on neurons . . . . . . . . . 45

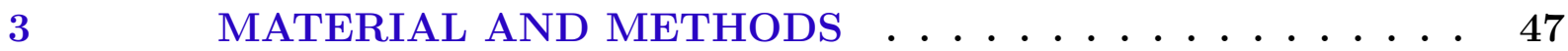

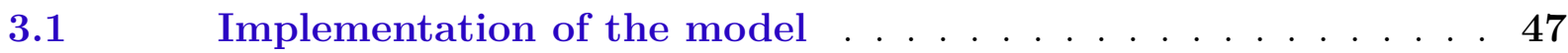

3.2 Simulations of synaptically isolated neurons . . . . . . . . 48

$3.2 .1 \quad$ Neuron models . . . . . . . . . . . . . . . . . . . . . . . . . . 48

3.2.2 Simulation of electric field on cortex surface . . . . . . . . . . . . 49

3.2.3 Simulation of current waveform in the TMS coil . . . . . . . . . . 51

3.2.4 Transforming neuron morphologies to follow cortical folding . . . . . . 52 
3.2.5 Coupling of the electric field to the neuron models . . . . . . . . . 53

3.2.6 Determination of excitation thresholds and action potential initiation sites . . . . . . . . . . . . . . . . . . 5 54

$3.3 \quad$ Neurons in a feedforward network . . . . . . . . . . 56

3.3.1 Modifications to L5 neuron model . . . . . . . . . . . . . . . 57

3.3.2 Synapses projecting onto L5 neuron . . . . . . . . . . . . . . . 57

3.3.3 Poisson spike trains on L2/3 neurons . . . . . . . . . . . . . . 59

3.3.4 Simulating epidural recordings after TMS pulse . . . . . . . . . . 59

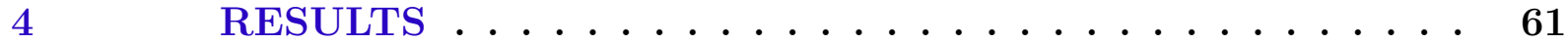

4.1 Synaptically isolated neurons . . . . . . . . . . 61

4.1.1 Sites of action potential initiation . . . . . . . . . . . . . 61

4.1.1.1 Stimulated neural elements . . . . . . . . . . . . . . . . . . 61

4.1.1.2 Alignment of neural elements to electric field vector . . . . . . . . . . . 62

4.1.2 Excitation thresholds . . . . . . . . . . . . . . . 62

4.1.2.1 Correlation between electric field components and excitation thresholds . . . 62

4.1.2.2 Variation of excitation thresholds with coil orientation . . . . . . . . . . 63

4.1.2.3 Variation of excitation thresholds with cell type . . . . . . . . . . . 63

$4.2 \quad$ Feedforward network model of cortical neurons . . . . . . . . 69

4.2.1 Simulated epidural response . . . . . . . . . . . . . . . . . . 69

4.2.2 Membrane potential of neuronal compartments . . . . . . . . . . . . 69

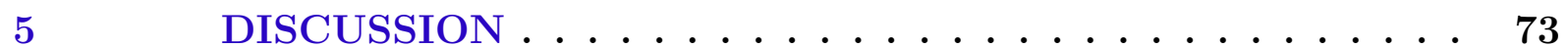

$5.1 \quad$ Synaptically isolated neurons under TMS pulse . . . . . . . 73

5.2 Cortical motor network under TMS pulse . . . . . . . . . 74

5.3 Conclusions . . . . . . . . . . . . . . . 75

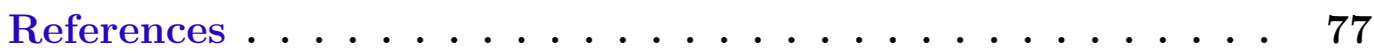




\section{Introduction}

\subsection{Motivation}

Techniques of brain stimulation are widely used and studied today in both diagnosis and therapy. Transcranial magnetic stimulation (TMS) employs magnetic fields to depolarize neurons and modulate cortical circuits with the advantage of being non-painful and non-invasive. However, the therapeutic potential of TMS is restricted by the lack of understanding about the exact neurophysiological effects of a given set of stimulation parameters. It is uncertain, for example, which neuronal elements are directly stimulated by a specific pulse waveform, and what are the cortical mechanisms that underlie TMS motor responses. Brain imaging and recording of epidural or muscular responses are too indirect to give a clear and precise picture of the effects at the cellular level. Furthermore, direct electrophysiological measurements have proven themselves difficult, being usually invasive or suffering from the strong electromagnetic coupling between stimulus and electrode.

Computational models are a complementary approach that allows the quantitative analysis of the influence of stimulation parameters over simulated neuronal membrane dynamics. By capturing and combining distinct physical phenomena involved in neurostimulation, it can make useful, experimentally testable predictions. However, no computational studies have been done including all three of subject-specific cortical geometry, complex neuronal morphologies, and synapses between neurons for the purpose of studying the effects of anatomical factors on the epidural response following TMS.

\subsection{Objectives}

The present work aimed to develop a computational model of the effects of transcranial magnetic stimulation on cortical neurons - first by applying the TMS pulse over a population of synaptically isolated neurons and afterwards over a feedforward network. 
The first stage involved reproducing the effects of change of extracellular potential on morphologically and biophysically detailed neuron models of cortical layer 2/3 (L2/3) and cortical layer 5 (L5) through calculation of quasipotentials based on an estimate of the electric field induced by TMS in a subject-specific head mesh, with the neurons being spatially arranged within the 3D model of the subject's brain; and then studying the sites of action potential initiation and the excitation thresholds.

The second stage expanded on the first stage by implementing synaptic connections between a subset of the neurons, resulting in a feedforward network of approximately 150 L2/3 neurons projecting onto a single L5 neuron, effectively simulating a neuronal circuit within the motor cortex. The output of the L5 neuron across repeated simulations was used to compose a simulated epidural response to the TMS pulse - allowing the analysis of the influence of neuroanatomy and neuronal morphology on the final signal and yielding explanations to experimental recordings. 


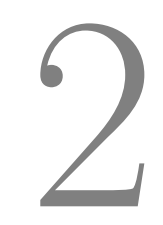

\section{Background}

\subsection{The human nervous system}

\subsubsection{Brain}

The human brain is a complex, multilayered structure, with thousands of specialized regions and dozens of functionally oriented subsystems (ANGEVINE et al., 1981). It contains, in total, at least 100 billion neurons (KANDEL, 2012), which are densely interwoven and interconnected, and have different electrophysiological and morphological properties.

The human brain is composed of four major parts: (I) the cerebrum (or telencephalon), (II) the diencephalon, (III) the cerebellum and (IV) the brain stem. The cerebrum is the largest and uppermost part of the brain, and includes the two hemispheres of the cerebral cortex along with subcortical structures such as hippocampus, basal ganglia and olfactory bulb. The two hemispheres of the brain are connected by the corpus callosum, a flat and thick bundle of fibres, and each hemisphere controls the opposing side of the body (i.e., the left hemisphere controls the right side of the body, and vice-versa).

The cerebral cortex (i.e., the outer layer of tissue in the cerebrum) is found only in mammals, and in larger mammals such as humans, the cortical surface is folded into gyri and sulci (Figure 1) to increase total surface area. The orientation of cortical neurons varies significantly due to this dense cortical folding.

Each hemisphere of the cortex can be divided into 4 lobes: frontal, parietal, temporal, and occipital (Figure 2). The frontal lobe - the largest of the lobes - includes the premotor and the primary motor cortices, and is therefore responsible for movement control, besides being responsible for action planning. The central sulcus separates the frontal and parietal lobes, while the lateral sulcus separates the frontal and temporal lobes. 
Figure 1 - Illustration of the folding of the cortical surface, showing the position of gyri and sulci along the folds.

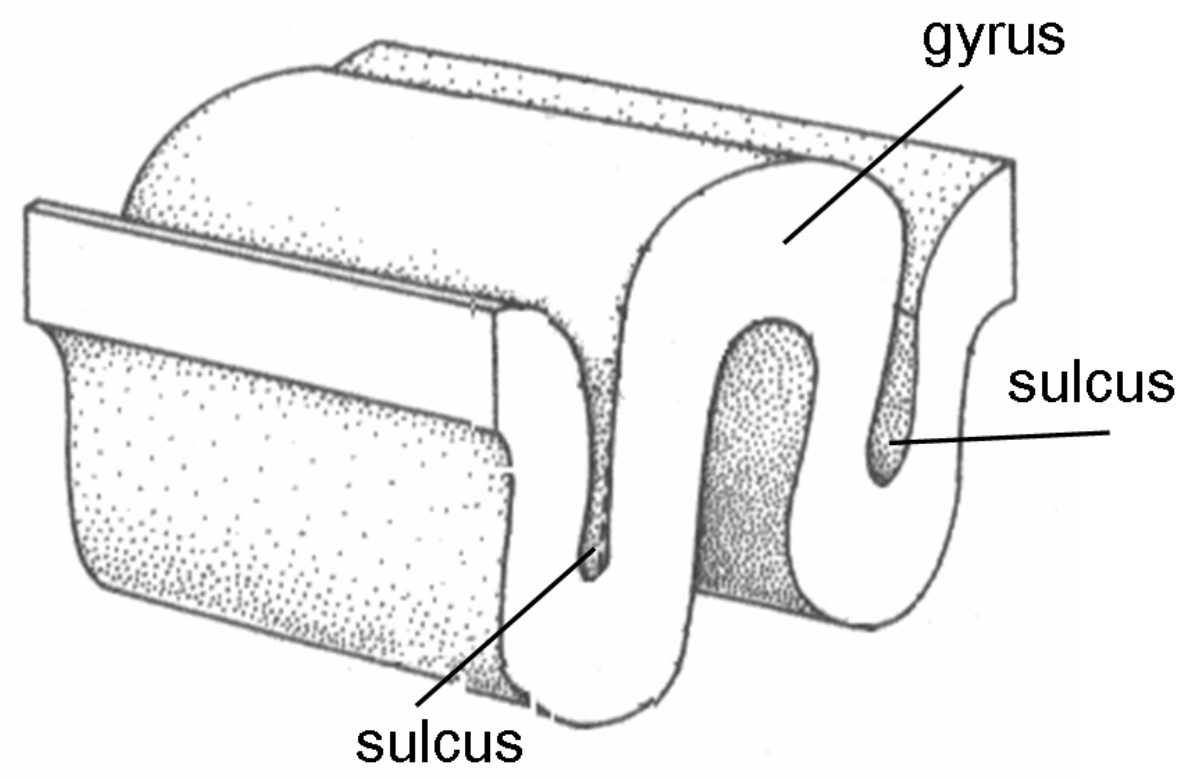

Figure 2 - Illustration of a lateral view of the human brain, indicating the brain lobes and the main gyri and sulci. Modified from (BLAUSEN, 2014).

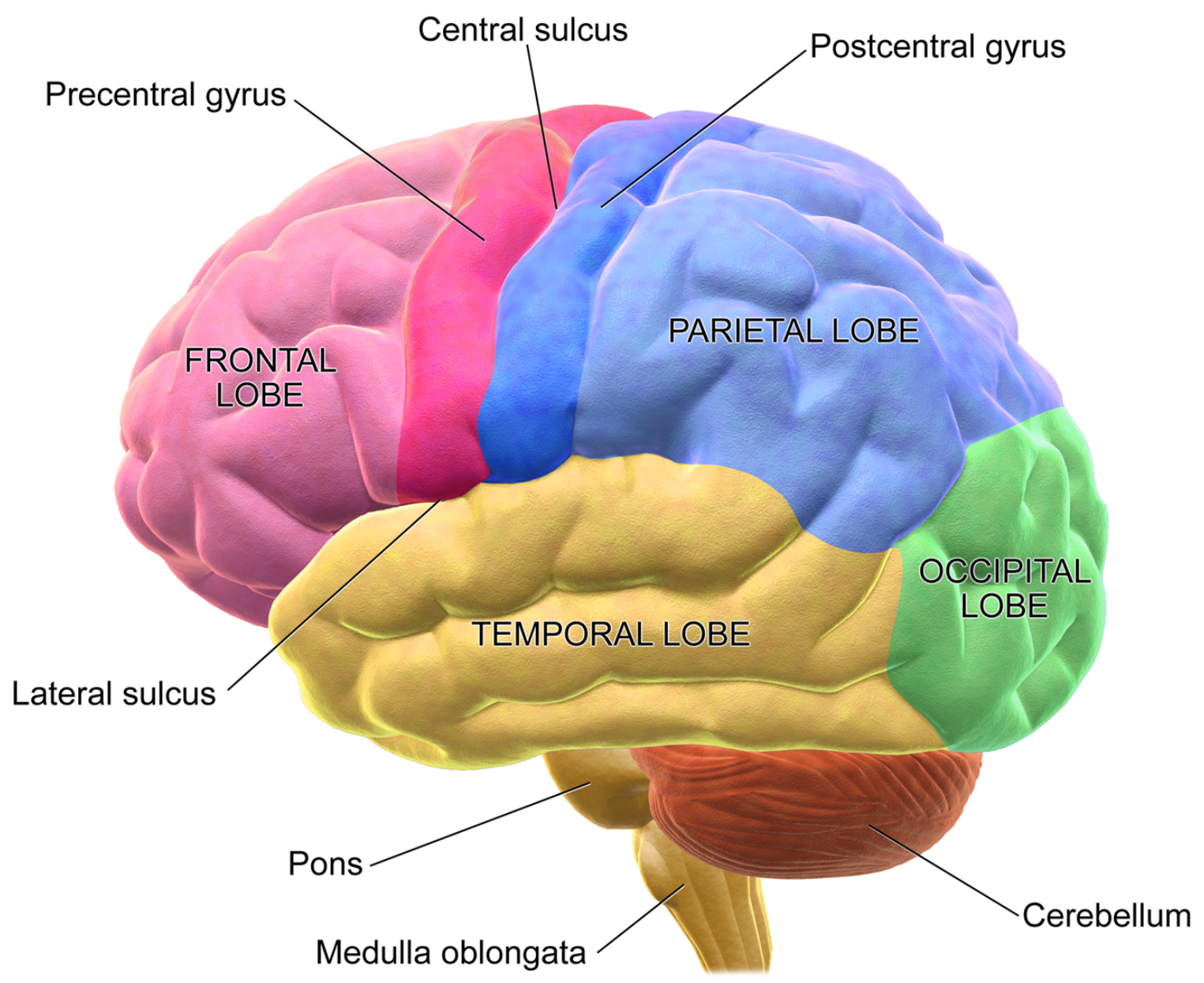


In mammals, three meninges (i.e., membranes) envelop the brain and the spinal cord for protection against injuries: the dura mater, the arachnoid mater, and the pia mater. The cerebrospinal fluid (CSF), a colorless fluid that acts as a cushion to the brain, is located in the subarachnoid space, between arachnoid mater and pia mater. The space between the two layers of the dura mater is called the epidural space, and exists around both the brain and the spinal cord (WAXMAN, 2009).

\subsubsection{Neurons}

The neuron is the primary cell of the nervous system, specialized for the processing and transmission of information. Neurons are electrically excitable, which means that they are capable of reacting to stimulation by producing a signal, called action potential. This excitation can be caused, for example, by chemicals arriving from other neurons through synapses (i.e., neurotransmitters), or by an external brain stimulation technique that generates an electric field, such as TMS. Action potentials are generated because of voltagegated ion channels embedded in the neuron's plasma membrane, which can open or close according to the value of the membrane potential. "Depolarization" is the increase of membrane potential, while "hyperpolarization" is the decrease.

A single neuron consists of dendrites, a cell body, and an axon (Figure 3). The cell body (also called soma) contains the nucleus of the cell, vital to cellular function. The dendrites receive and combine signals arriving from other neurons through synapses, while the axon transmits the action potential generated at the neuron. A single cortical neuron can be connected to thousands or tens of thousands of different neurons (KANDEL, 2012), which can be located in different brain regions within any of the cerebral hemispheres.

The pyramidal neurons, named as such due to their pyramidal cell body shape, are the most numerous excitatory cell type in mammalian cortices (SPRUSTON, 2009). They possess two distinct dendritic trees - the basal and the apical - which emerge from the base and the apex of the cell body, respectively - with the apical dendrites extending toward the pial surface.

\subsubsection{Motor cortex}

The main role of the motor cortex is the planning and execution of voluntary movement (KANDEL, 2012). It is localized immediately rostral to the central sulcus (Figure 2), within the frontal lobe, and can be divided in three areas: the primary motor cortex (M1), the premotor cortex (PM), and the supplementary motor area (SMA). External stimulation of these areas elicits movements of specific body parts.

The primary motor cortex is located on the precentral gyrus. Activation of this area can be achieved with brief and low intensity external stimulation, and results in movement of individual body parts. On the other hand, stimulation of PM and SMA require 
Figure 3 - Illustration of a multipolar neuron with myelinated axon, indicating its main structures. Modified from (BETTS et al., 2013).

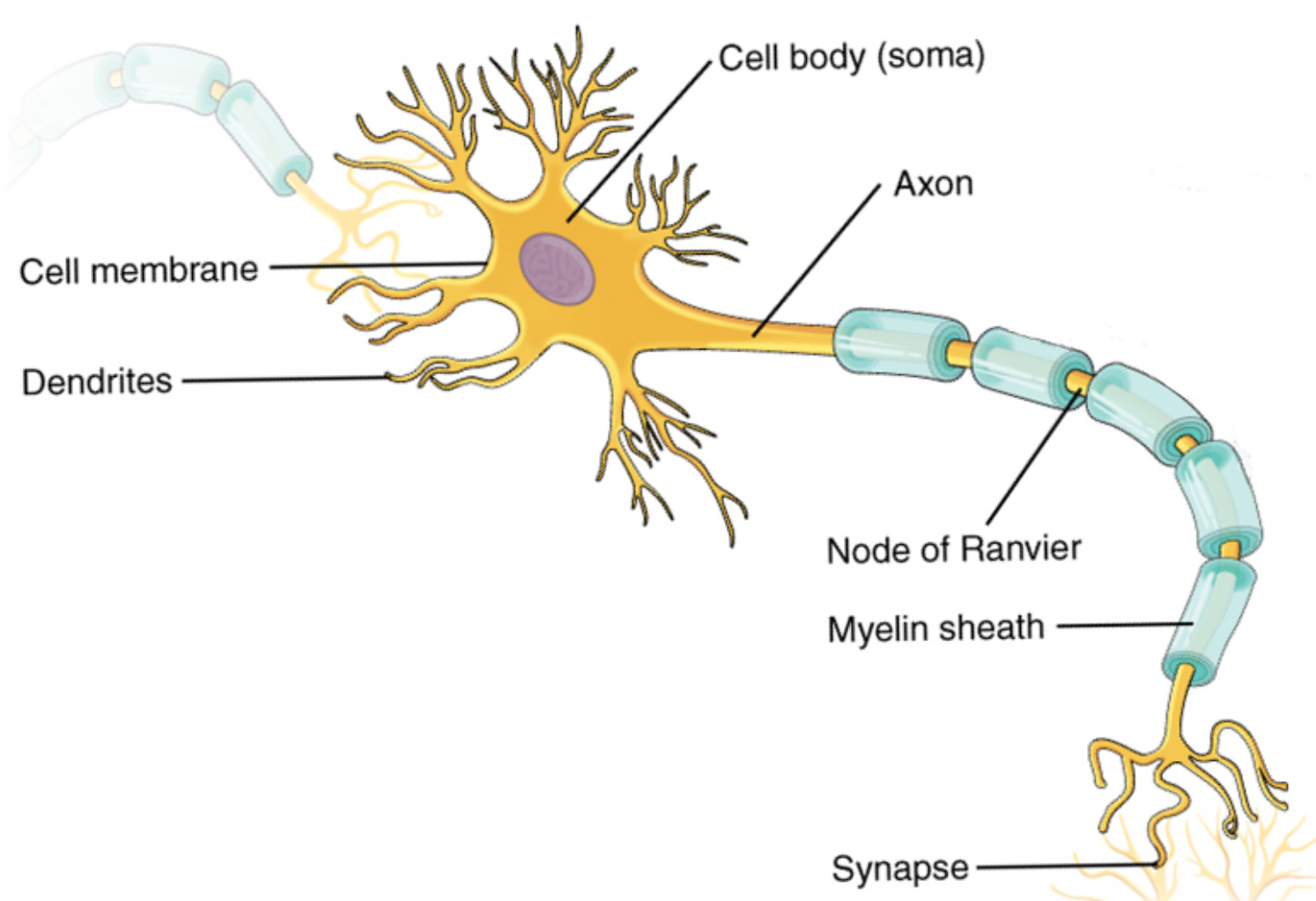

higher intensities of stimulus and tend to elicit more complex and stereotyped movements; therefore, they appear to encode complex patterns of planned, goal-oriented motor output.

In the resting motor cortex, the most prominent pattern of oscillating neuronal activity is the $\mathrm{mu}(\mu)$ rhythm, having a frequency that ranges from 7.5 to $12.5 \mathrm{~Hz}$ (SCHOMER, 2010).

\subsection{Transcranial magnetic stimulation}

In the eighteenth century, Luigi Galvani was among the first scientists to study the effects of electricity applied on the human body, founding the field of electrophysiology (HORVATH et al., 2010). In 1980, Merton and Morton (MERTON; MORTON, 1980) successfully stimulated the motor cortex using transcranial electrical stimulation (TES). Anthony T. Barker and colleagues (BARKER; JALINOUS; FREESTON, 1985), seeking to reduce the painfulness of this type of stimulation, investigated the use of magnetic fields and, in 1985, developed the first stable device of transcranial magnetic stimulation (BARKER; FREESTON, 2007). 


\subsubsection{Definition}

Transcranial magnetic stimulation (TMS) is a noninvasive technique for stimulation of the human brain using magnetically induced electric fields, which are capable of eliciting or modulating neuron activity in superficial parts of the brain. It has been widely used in studies of motor and cognitive functions and, experimentally, in clinical treatment (HALLETT, 2007).

TMS can be used to excite or inhibit neurons according to stimulation parameters - which therefore allows, e.g., functional mapping of cortical regions, or production of transient functional lesions (HALLETT, 2000). For example, when applied in the motor cortex, TMS can produce a muscle twitch, or block movements; when used in the occipital cortex, TMS can produce visual phosphenes (HALLETT, 2000). Therefore, it is commonly used in assessing motor pathways and locating eloquent cortical areas during presurgical planning. Most TMS studies have involved the motor cortex.

Single-pulse TMS is non-painful and safe (HALLETT, 2000). Repetitive TMS (rTMS) can produce long-lasting effects in the brain beyond the time of stimulation due to effects on neuroplasticity, and therefore shows potential for therapy, but with possible adverse effects (HALLETT, 2000).

\subsubsection{Applications}

The general applications of TMS are diverse, such as investigation of information processing in the brain, treatment of neurological disorders, assessment of damage or the progress of disease in nerve pathways, and activation of cortical plasticity (BARKER; FREESTON, 2007). In the United States, TMS is approved by the Food and Drug Administration (FDA) for the treatment of depression, migraine and obsessive compulsive disorder, and for presurgical cortical mapping (ELDAIEF; PRESS; PASCUAL-LEONE, 2013).

\subsubsection{TMS for functional mapping}

TMS mapping of the motor cortex has been used to study the cortical representation of motor activation, motor learning and others (THICKBROOM; SAMMUT; MASTAGLIA, 1998). Functional hemodynamic imaging methods, e.g. PET (positron emission tomography) and fMRI (functional magnetic resonance imaging), can be used to probe the relationship of a brain region to a cognitive function, but they have low time resolution (in the order of seconds), and are not enough to prove that an area is essential for a specific function (HALLETT, 2000). Since TMS can disrupt activity in selected brain regions, it has the advantage of assessing function in a millisecond scale (HALLETT, 2000). However, the potential of TMS alone is relatively limited; it is much more useful when 
combined with electrophysiological measurements - e.g., EEG -, imaging - e.g., PET, fMRI, near infrared spectroscopy (NIRS), magnetic resonance spectroscopy (MRS) -, or exposure to drugs - i.e., pharmaco-TMS (ZIEMANN, 2011). Functional connectivities among different cortical areas can also be revealed by a combination of TMS with imaging (TERAO; UGAWA, 2002).

\subsubsection{TMS for studying cortical excitability}

Both excitatory and inhibitory effects can be achieved using TMS, and they can be investigated through measures of the resulting activity in nerve fibers or muscles. The muscular response to magnetic stimulation of M1 can be recorded through electromyography (EMG), and the resulting activity signal is called motor evoked potential (MEP). Since the amplitude of MEPs is correlated to cortex excitability (CONFORTO et al., 2004), their recording has provided insight into the excitability phenomena produced by magnetic stimulation (ROSSINI et al., 2015) (JESUS et al., 2014).

The epidural response (i.e., volleys descending through the corticospinal tract) has also been measured in human subject studies (LAZZARO et al., 1998) (LAZZARO et al., 2001). The oscillations in the epidural signal following TMS can be categorized in two groups: direct (D) and indirect (I) waves. The D-waves are the volleys of activity supposed to be produced by direct activation of corticospinal neurons (i.e., the pyramidal neurons of the 5th layer of the motor cortex). I-waves, conversely, are presumed to be the result of activation of neurons presynaptic to the corticospinal neurons, possibly involving recurrent connections. The duration and latencies of the waves are influenced by direction of the current induced in brain tissue (and consequently coil orientation) (LAZZARO et al., 2001), muscle contraction, coil current waveform and stimulation intensity.

When used for peripheral nerve stimulation, magnetic stimulation has a similar mechanism of activation as electrical stimulation (TERAO; UGAWA, 2002). However, different mechanisms appear when the techniques are used for brain stimulation. Electrical stimulation tends to activate the descending axons of the corticospinal tract directly, producing D-waves (direct waves). On the other hand, TMS tends to activate pyramidal neurons transsynaptically, producing I-waves (indirect waves) (TERAO; UGAWA, 2002) which have higher latency. However, I-waves can happen in both types of stimulation, and the mechanism of I-wave production is not completely clear (HALLETT, 2007).

If a single TMS pulse is applied over M1 during a continuous voluntary muscle contraction, a brief suppression of activity can be seen in the recorded electromyographic signal (EMG) (JESUS et al., 2014) (GRUET et al., 2013). This is called the cortical silent period (CSP), and can be divided into spinal and cortical components, which are mediated by spinal refractoriness and cortical inhibition, respectively (JESUS et al., 2014). This cortical inhibition seems to be mediated by GABA $_{B}$ receptors (HALLETT, 2007) (MOEZZI et al., 2018). 


\subsubsection{Basic physics of TMS}

TMS is based on the physical principle of electromagnetic induction: an electric field can be produced by a time-varying magnetic field. In turn, an electric field can produce currents through conducting media, such as ionic solutions in biological tissue.

In TMS, the generation of time-varying magnetic fields is achieved by passing a brief, varying electric current through a coil. The magnetic field can reach up to about 2 Tesla and typically lasts for about $100 \mathrm{~ms}$ (HALLETT, 2007), with the induced electric field being always perpendicular to the magnetic field. In the brain, the induced current flows parallel to the plane of the coil and, therefore, tangential to cortical surface.

For the most common coils (circular or figure-of-eight coils), the effective magnetic field falls off rapidly with distance from the coil. The electric field penetrates at around $2 \mathrm{~cm}$ (EPSTEIN et al., 1990) and, at most, $4 \mathrm{~cm}$ of the brain tissue - such as when stimulating the leg motor area (TERAO et al., 2000) -, which means that the tissues stimulated are usually only the closest to the scalp, such as gray matter or subcortical white matter (TERAO; UGAWA, 2002).

\subsubsection{TMS coils}

Magnetic coils used in TMS are available in different shapes. In any type of coil, there is a trade-off between depth of the stimulation and the focality; i.e., the more focal the stimulation achieved by the coil, the less deep the region that can be stimulated. Circular coils induce eddy current underneath the course of the coil winding, but in the direction reverse to the coil current (TERAO; UGAWA, 2002). A figure-of-eight coil is composed of two wires of coils arranged side by side with the current in each being in opposite directions (TERAO; UGAWA, 2002). Figure-of-eight coils are more focal than the older round coils, since they allow for electric field intensity to add below the intersection of the two round coil wirings, and, therefore, for maximal induced current to occur at that point. As such, they are more commonly used.

\subsubsection{Current waveforms}

The magnetic stimulation device can be visualized as a capacitor with a large capacitance connected to a coil with specific resistance and inductance (TERAO; UGAWA, 2002). To generate a brain-stimulating electric field, the current flowing through the coil - which is, therefore, part of an resistor-inductor-capacitor (RLC) circuit - can be set to follow different time profiles - denominated current waveforms - by varying the resistance, inductance and capacitance values. The current induced in the tissue is positive (i.e., aligned with the handle-to-coil direction) when the current in the coil is increasing, and negative when the current is decreasing. 
Figure 4-Most common coil current waveforms in TMS: monophasic and biphasic. Adapted from Wasserman et al. 2008 (WASSERMAN; EPSTEIN; ZIEMANN, 2008).
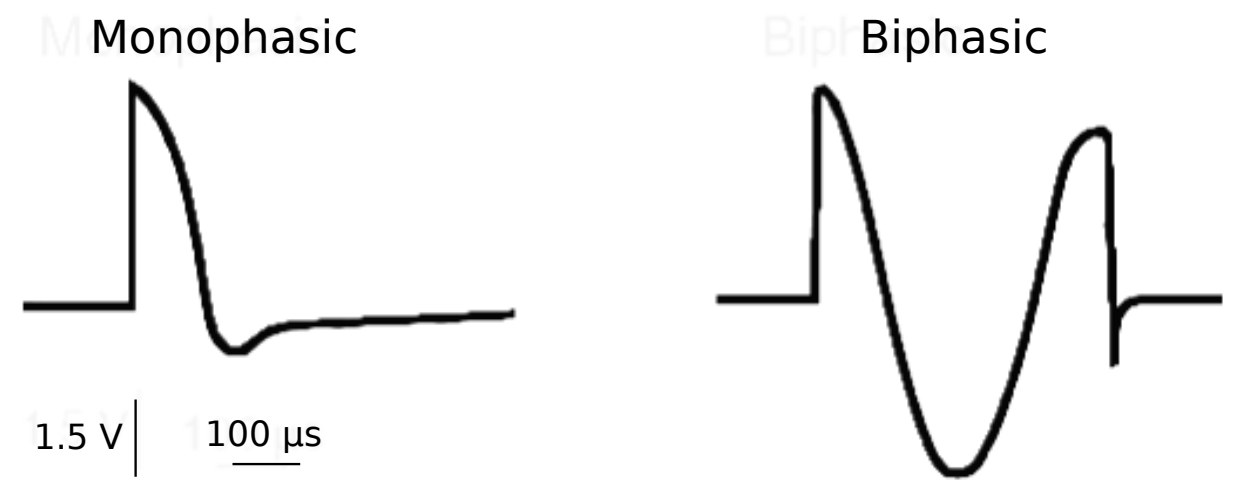

The two current waveforms most commonly used in TMS are the monophasic and the biphasic (Figure 4). The monophasic pulse is achieved by dampening the first quarter cycle of the sinusoidal RLC circuit current, resulting in a mostly unidirectional induced current flow (since the electric field is of a single polarity during the first, rapidly-changing and high amplitude phase of its time course). The biphasic pulse is achieved by allowing the current to follow a full sine cycle. This results in an induced current flow of two polarities (i.e., two opposite current directions), one in each half of the cycle and with equal amplitudes.

Biphasic pulses are more effective (i.e., have lower motor thresholds) than monophasic pulses at the motor hand area, when considering equal amplitudes of initial current. Monophasic pulses are more effective when the current induced at the motor cortex is in a postero-anterior (PA) direction instead of a antero-posterior (AP) direction (KAMMER et al., 2001).

\subsubsection{Electromagnetic equations}

Maxwell's equations. Maxwell's equations are the foundation of classical electromagnetism and describe how charges, currents and changing fields create electromagnetic fields. In their differential form, they are stated as:

$$
\begin{aligned}
\nabla \times \mathbf{E} & =-\frac{\partial \mathbf{B}}{\partial t}, & & \text { (Faraday's law) } \\
\nabla \times \mathbf{B} & =\epsilon_{0}\left(\mathbf{J}+\mu_{0} \frac{\partial \mathbf{E}}{\partial t}\right), & & \text { (Ampère's law) } \\
\nabla \cdot \mathbf{B} & =0, & & \text { (Gauss' law) } \\
\nabla \cdot \mathbf{E} & =\frac{\rho}{\epsilon_{0}} & & \text { (Coulomb's law) }
\end{aligned}
$$

where symbols in bold denote vectorial quantities; $\nabla \cdot$ denotes the divergence operator; 
$\nabla \times$, the curl operator; t, time; E, electric field; $\mathbf{B}$, magnetic field; $\rho$, the electric charge density; $\epsilon_{0}$, the permittivity of free space; $\mu_{0}$, the permeability of free space; and $\mathbf{J}$, current density. TMS is based on electromagnetic induction, described by Faraday's law above.

Primary and secondary electric fields. The magnetic field generated by TMS, on its own, has no effect over the neurons, and it merely mediates the interaction (RUOHONEN, 2005). The total electric field on the tissue is the sum of primary and secondary electric fields. The primary electric field is the applied field (i.e., the electric field resulting from the pulse in the coil) and would induce a flow of current $\mathbf{J}$ if the medium had a single value sigma of homogeneous conductivity. However, conductivity changes along the path of the induced current causes accumulation of charges (due to conservation of current), which create the secondary electric field.

If the magnetic field $\mathbf{B}$ is expressed in terms of vector potential $\mathbf{A}$, the total electric field $\mathbf{E}$ can be stated as:

$$
\mathbf{E}=\mathbf{E}_{1}+\mathbf{E}_{2}=\frac{\partial \mathbf{A}}{\partial t}-\nabla V
$$

where $\mathbf{E}_{1}$ and $\mathbf{E}_{2}$ are primary and secondary electric fields; $t$, time; $V$, electric potential. The electric potential $V$ obeys Laplace's equation: $\nabla^{2} V=0$.

At cellular level, the physiological principles of TMS and TES are equivalent (RUOHONEN, 2005). The electric field causes free charges to move within and outside the cells, inducing ionic currents in the biological tissue. When this flow is interrupted by pieces of the membrane, a charge buildup arises, charging the membrane capacitances. Subsequently, action potentials are triggered.

\subsubsection{Calculation of the electric field induced in the brain}

Accurate numerical estimates of the fields involved in brain stimulation are necessary to quantitatively characterize the spatial extent of the stimulated region and understand its physiological effects.

Commonly, in subject-specific computational simulations of the electric field induced by the TMS coil, the first step is the calculation of the magnetic field induced by the coil shape (NEGGERS et al., 2015). Conductivity values, either isotropic or anisotropic, are assigned to the different head tissues before the process. Usually, the TMS coils are modeled with magnetic dipoles, which allows the determination of the magnetic vector potential at each node of the subject-specific tissue meshes through the summation of all dipoles (THIELSCHER; OPITZ; WINDHOFF, 2011). Afterwards, the magnetic vector potential is used as input for the calculation of the electric field vectors, through the finite element method (FEM) or boundary element method (BEM), and under the quasi-static assumption (WINDHOFF; OPITZ; THIELSCHER, 2013). 


\subsubsection{SimNIBS software}

SimNIBS (THIELSCHER; ANTUNES; SATURNINO, 2015) is a free, open-source software package for simulation of electric fields generated during non-invasive brain stimulation (NIBS) modalities. It supports the subject-specific calculation of the induced electric field for two modalities (tDCS and TMS) based on finite element method (FEM).

The SimNIBS workflow for a TMS simulation consists of three parts: generation of the 3D head mesh from MRI images; calculation of fields (e.g., electric field and current density) from predefined coil parameters (shape, position and orientation); and postprocessing.

For the simulation of TMS-induced electric fields, SimNIBS receives as input a polygon mesh file of the head of the subject, a coil definition file, and a list containing the position and orientation of the TMS coil and the pulse intensity. Values of anisotropic conductivity derived from diffusion tensor imaging (DTI) data can be specified for gray matter and white matter tissues. The volume normalized mapping uses the anisotropy tensors while keeping the mean conductivity of the tensors at a constant value, such as the conductivity for the isotropic case (WINDHOFF; OPITZ; THIELSCHER, 2013). Afterwards, the simulation can be run, with the electric field induced by the TMS coil being calculated with equation 2.2 (THIELSCHER; ANTUNES; SATURNINO, 2015). The simulation results are stored in several files, the most relevant of which is the file containing the calculated fields, in ".msh" format. This .msh file can be loaded and visualized through the gmsh software.

The fields calculated in the FEM calculations include the vectorial electric field (designed as "E" in SimNIBS interface); the electric field magnitude ("normE"); the current density vector field ("J"); the current density magnitude ("normJ"); and the scalar electric potential ("v").

SimNIBS uses segmentation algorithms for the reconstruction of a head polygon mesh from structural magnetic resonance images (either T1-weighted or T2-weighted). For brain segmentation, the FreeSurfer package is used by SimNIBS; for other head structures, BET/BETsurf from the FSL library is used.

\subsection{Modeling of neuronal membrane dynam- ics}

In neurons, the generation of action potentials depends on passive membrane properties (e.g., as capacitance and leak conductance) and active membrane properties (e.g., ion channel densities and kinetics). As such, computational models must include both passive and active membrane properties and the coupling of external electric fields to 
the membranes to accurately predict the neural responses to stimulation (ABERRA; PETERCHEV; GRILL, 2018).

\subsubsection{Basic neuronal modeling}

Conductance-based models are a biophysical representation of an excitable cell, such as a neuron, in which its phospholipid bilayer (i.e., the molecular structure of the cell's membrane) is modeled as a capacitor, and ion channels embedded in the layer are modeled as conductances - i.e., they allow the representation and simulation of the cell membrane and ionic currents as an electrical circuit (SKINNER, 2006). This allows the modeling of electrical signals (i.e., variations in membrane potential, including action potentials) in the cell by means of equations, which can be numerically solved in a computer - usually within simulation environments such as NEURON, which facilitate this implementation.

If a neuron cell is considered as being a capacitive membrane with ohmic, conductive saline solutions inside and outside, then, through laws of conservation of charge and current, a differential equation (independent of the specific model of the membrane) can be derived. This equation is called the cable equation, and the set of these assumptions and derivations is called the "cable theory", or the "cable model" (NIEBUR, 2008) (HOBBIE, 2015). Within the NEURON environment, the propagation of signals through a non-branched cable is described by the following simplified cable equation (HINES; CARNEVALE, 1997):

$$
\frac{\partial V}{\partial t}+I(V, t)=\frac{\partial^{2} V}{\partial^{2} x}
$$

where $V$ is the transmembrane potential; $I$, transmembrane current; $x$, position along the cable's longitudinal axis; and $t$, time.

However, many such differential equations, which model complex physical phenomena, do not have analytical solutions; therefore, numerical approximations of their solutions are needed if one aims to quantitatively study such types of problems. In numerical models of neurons, time and space need to be discretized; this discretization replaces the partial differential equation (PDEs) of the cable model with a coupled system of ordinary differential equations (ODEs). Since the neuronal processes, which extend in space, are also discretized, each isopotential component of the neuronal process is called a "compartment" (SKINNER, 2006). Within the NEURON simulation environment, a compartment is denominated "segment", and a series of compartments are connected by resistors - with voltage, therefore, varying linearly between centers of adjacent compartments (HINES; CARNEVALE, 1997). 


\subsubsection{Neuronal effects of stimulation}

In peripheral nerve stimulation, it has been shown experimentally that long straight axons are polarized at the gradient of the electric field component aligned with the axon, and that stimulation would occur at the sites where this component is decreasing most rapidly along the direction of the nerve (ROTH, 1994) (SALVADOR et al., 2011).

According to cable theory and models of neurostimulation, regular neuronal elements (such as long peripheral nerves) can be activated by external electric fields by two main mechanisms: if the field is parallel to the neuronal element, then the field will be more effective where the change of intensity, as a function of distance, occurs more abruptly. Otherwise, if the field is not parallel or is uniform, activation will occur at discontinuities such as terminations or bends (Figure 5) (HALLETT, 2007). However, in cortical neurons with complex morphology, the exact description of sites of excitation is more complicated (ROTH, 1994), and one must simplify calculations with some assumptions to efficiently capture the important aspects of simulation of the cortical neurons in a model.

Figure 5 - Illustration of the main mechanisms of activation of long axons by an external electric field. Depolarization of the membrane of the axon is indicated (D for depolarization, and $\mathrm{H}$ for hyperpolarization) for a given eletric field orientation (arrows). (A) Uniform electric field, causing no polarization with respect to resting axon. (B) Varying electric field (i.e., gradient), causing regions of depolarization. (C) Uniform electric field with bent axon, causing depolarization. Adapted from (HALLETT; CHOKROVERTY, 2005).

(A)

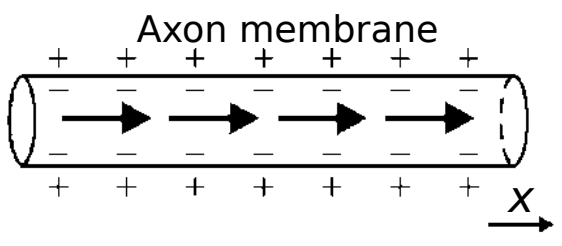

(B)

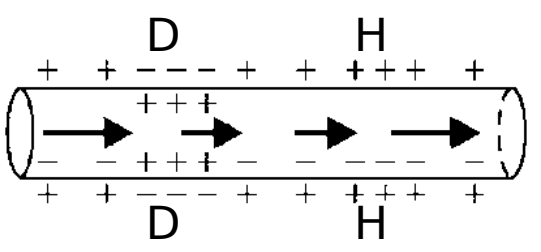

(C)

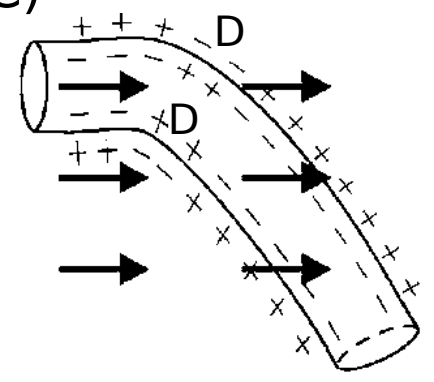

\subsubsection{Quasistatic approximation}

The quasistatic approximation assumes that electromagnetic fields vary slowly enough with time so that equations (including 2.1) can be kept at a static form (i.e., not involving time derivatives), and, as such, propagation, inductive and capacitive effects can be ignored. For modeling bioelectric sources, which involve frequencies below $1 \mathrm{kHz}$, this approximation has been shown to be valid (PLONSEY; HEPPNER, 1967), and, for modeling external stimulation, which involves frequencies above $1 \mathrm{kHz}$ (e.g., pulse widths 
of $25 \mu \mathrm{s}-1 \mathrm{~ms}$ ), it has been shown to be sufficiently accurate for appropriate values of conductivity (BOSSETTI; BIRDNO; GRILL, 2007). In the case of stimulation modeling, this approximation allows the electric field solution to be separated into spatial and temporal components. For a computational model of the effects of TMS, the derivative of the coil current waveform can be used to scale the spatial component of the electric field, resulting in the approximation of the final electric field solution as function of both space and time (GOODWIN; BUTSON, 2015). Additionally, since neuronal numerical models require the electric field to be expressed as extracellular potentials so that their effect over the neuron's transmembrane potential can be calculated (APPUKUTTAN; BRAIN; MANCHANDA, 2017) (JOUCLA; YVERT, 2012), the quasi-static assumption allows the spatial component of the electric field to be rewritten as electric potentials (quasipotentials) through numerical integration. In computational simulations, the calculation of quasipotentials by numerical integration of the electric field allows for a simple and accurate coupling of magnetically induced electric fields to neuron membrane dynamics (WANG; GRILL; PETERCHEV, 2018).

It can also be assumed that, on the scale of a neuron, electric field gradients are not significant enough to contribute to the neuron's polarization. This is called a quasiuniform assumption. For transcranial electric and magnetic stimulation, this assumption is reasonable, since the scalp electrodes of TES are macroscopic and the coil of TMS is at a macroscopic distance from the brain (BIKSON; DMOCHOWSKI; RAHMAN, 2013). However, when considering neuronal morphological discontinuities such as terminals, bends and branches, the uniform electric field is enough to cause depolarization or hyperpolarization at these discontinuities.

\subsubsection{Modeling extracellular fields}

External electric fields affect neurons due to their influence over the extracellular potentials. A simplification such as the activating function (RATTAY, 1986) could be used to approximate the transmembrane currents produced by the external stimulus; however, a more direct way of simulating external stimulation is by representing the extracellular space adjacent to the neuron's membrane as additional nodes in the model's electrical circuit, and then manipulating the value of electric potential at these nodes so that they follow the stimulus' time course. The resulting transmembrane currents in the several compartments of the neuron can then be directly simulated by simulating the currents in the electrical circuit. The NEURON simulator supports the implementation of extracellular fields in this manner (APPUKUTTAN; BRAIN; MANCHANDA, 2017). The advantage of this approach is that the extracellular potential is independent of the electrophysiological properties of the neuron model, which allows its usage in the context of any problem in which it is possible to calculate the extracellular potential produced by the stimulus, and at the proximity of any neuron model with detailed morphology. 
The electric field induced by magnetic stimulation cannot be expressed in scalar electric potentials because it is non-conservative. Therefore, the quasistatic approximation must be assumed beforehand so it can be expressed in the form of electric potentials (i.e., quasipotentials).

\subsubsection{Neuronal effects of TMS}

Different hypotheses exist concerning the orientation of neural elements preferentially activated by TMS. Since current paths in magnetic stimulation are parallel (i.e., tangential) to the cortical surface, it has been suggested that the neural elements oriented perpendicularly (i.e., radially, or in the direction of cortical columns) to the cortical surface are the most activated during TMS (FOX et al., 2004). Previously, Day et al. 1989 (DAY et al., 1989) had hypothesized that strength of the induced current would outweigh other factors and that, therefore, magnitude of electric field would be the greatest factor in neuronal activation.

Studies using TMS on visual and motor areas have suggested that the amplitude of the induced charge accumulation is more important for stimulation than the amplitude of the induced current (CORTHOUT; BARKER; COWEY, 2001), but more studies are necessary for extending this conclusion to other cortical areas (TERAO; UGAWA, 2002).

\subsubsection{Unanswered questions on the TMS mechanism of activa- tion}

The theory behind TMS-generated macroscopic electromagnetic fields, the electrical operation of the TMS device circuit, and the principles of cellular events leading to action potential generation in a neuron are well understood (RUOHONEN, 2005). However, the underlying physiological mechanism through which the neurons are activated in magnetic stimulation and related stimulation modalities is still poorly understood, because of the complex interaction between the currents induced in the brain tissue and both the components of neuron morphology and the cortical circuits (LAZZARO; ZIEMANN; LEMON, 2008). For example, the effects of neuron morphology, boundaries between gray and white matters, local tissue anisotropy, glial cells, and background neuronal activity are largely unknown (RUOHONEN, 2005). The diverse types and properties of tissues in the central nervous system result in an inhomogeneous and anisotropic conductivity distribution, which distorts the induced electric field in a nontrivial way (OPITZ et al., 2011). In addition, it remains to be demonstrated how the efficacy and reliability of their application are influenced by different stimulation parameters (DAVILA-PÉREZ et al., 2018). This lack of understanding hinders the effective and rational use of these stimulation techniques. 


\subsubsection{Computational models of TMS effects on neurons}

Experimental studies of the activation phenomena following TMS rely on indirect measurements, such as brain imaging, electrophysiological recordings (e.g. EEG), and muscular responses (e.g. EMG). Besides, the strong coupling between the stimulating fields and electrodes is an obstacle for direct in vivo recording from neurons (MUELLER et al., 2014) (ABERRA; PETERCHEV; GRILL, 2018). Therefore, the use of experimental techniques alone is insufficient to determine which neuronal elements and populations are activated by stimulation with a given set of spatial and temporal parameters.

As such, computational models of the neuronal effects of stimulation provide a quantitative approach to understand the stimulation mechanisms and optimize stimulation parameters (WANG; GRILL; PETERCHEV, 2018), since they can be used to efficiently explore the parameter space and to generate testable predictions.

The neuronal effects of TMS have been studied computationally with synaptically isolated neurons embedded in a simplified sulcal geometry (SALVADOR et al., 2011) or in a MRI-segmented cortical surface (SEO et al., 2017). However, these studies did not include complete, realistic axonal morphology, which is supposed to contain multiple sensible sites of excitation (ABERRA; PETERCHEV; GRILL, 2018) (ABERRA et al., 2020).

Models of the effects of TMS on feedforward networks have been done including morphologically complex L5 pyramidal neuron models and abstract L23 point neuron models simultaneously, studying the effects of stimulation parameters and brain circuits dynamics on oscillations seen in descending volleys (RUSU et al., 2014) (SCHAWORONKOW; TRIESCH, 2017) and on simulated electromyographic signal (MOEZZI et al., 2018). However, in these studies, the TMS pulse is applied over the neurons as current injection to the somas or to the partial axons, instead of as manipulation of values of extracellular quasipotentials close to neurons (JOUCLA; YVERT, 2012) with realistic axonal arborizations (ABERRA et al., 2020).

The effects of TMS-induced electric field on neuronal morphological elements have been studied in isolated neurons with the inclusion of intricate axonal arborization (ABERRA; PETERCHEV; GRILL, 2018) (ABERRA et al., 2020), yielding results about the sites of action potential initiation.

However, no computational studies have been done including all three of subjectspecific MRI-segmented cortical geometry, complex axonal morphologies of L23 and L5 neurons, and synapses between both layers of neurons in a feedforward architecture, for the purpose of studying the effects of neuron morphology and cortex geometry on the epidural response. 



\section{Material and methods}

\subsection{Implementation of the model}

Simulations and analysis of results were implemented in the high-level, general-purpose Python programming language. The NEURON-Python library (HINES, 2009) was used for interfacing the Python 2.7 code with the NEURON 7.5 simulation environment (HINES; CARNEVAle, 2001) (CARNEVAle, 2006). The NumPy 1.16 .5 (WALT; COLBERT; VAROQUAUX, 2011) and SciPy 1.2.1 (VIRTANEN et al., 2020) Python libraries were used for numerical processing, and matplotlib 2.2.4 (HUNTER, 2007) for plotting of results. The Visualization Toolkit (VTK) 3D graphics processing software (SCHROEDER; MARTIN; LORENSEN, 2002) and its interfacing Python library (PYTHON-VTK..., 2020) were used, along with the PyMesh library (ZHOU, 2020), for 3D mesh processing involved in the spatial transformations of morphologies of neuron models. The high-level Python library Brain Modeling Toolkit (BMTK 0.0.8) (GRATIY et al., 2018) was used for facilitating the implementation and simulation of the network of multicompartmental neurons. All NEURON simulations were run with a time step of $0.025 \mathrm{~ms}$.

Code was implemented in two parts, with the purpose of simulating and analyzing two types of effects of a single TMS pulse on neuronal models spatially arranged within a 3D model of a human brain: first, on a population of synaptically isolated neurons; and second, on neurons in a motor cortex, feedforward network. 


\subsection{Simulations of synaptically isolated neu- rons}

\subsubsection{Neuron models}

For the simulation of membrane potential dynamics of cortical neurons, morphologically realistic conductance-based, multi-compartmental models of pyramidal neocortical neurons (MARKRAM et al., 2015) of two cortical layers - L2/3 (Figure 6) and L5 - were replicated and geometrically transformed within a 3D model of an individual brain to imitate the arrangement of columns of pyramidal neurons in the human cortex. These neuron models were published by the Blue Brain Project (MARKRAM et al., 2015) and were morphologically reconstructed from slices of the somatosensory cortex of Wistar rats, including realistically intricate axonal arborization. The models were later modified by Aberra et al. (ABERRA; PETERCHEV; GRILL, 2018) to include myelination so that their electrophysiological properties are closer to the properties of an adult human cortical neuron. The realistic axonal morphology makes them suitable for accurate numerical modeling of the effects of externally applied electric fields, since the axon is suspected to contain the main sites of activation by different stimulation modalities, including TMS (NOWAK; BULLIER, 1998) (CHAKRABORTY et al., 2017).

The neurons modeled kinetics of 13 ion channel currents (MARKRAM et al., 2015), including persistent sodium, transient potassium, persistent potassium, m-current, hcurrent, high voltage-activated calcium, low voltage-activated calcium, Kv3.1, d-type potassium, stochastic potassium, and SK calcium-activated potassium. All ionic currents followed the Hodgkin-Huxley formalism:

$$
I=\bar{g} \cdot m^{x} \cdot h^{y}(V-U),
$$

where $\bar{g}$ is the maximal conductance; $x$ and $y$, number of gate activation or inactivation variables, respectively; $U$, the reversal potential of the respective ion; $V$, the transmembrane potential.

The ion channel mechanisms were distributed uniformly in the basal dendrites, apical dendrites, soma, axon initial segment, with the exception of $\mathrm{I}_{h}$ (h-current) which was distributed exponentially in apical dendrites (MARKRAM et al., 2015). 
Figure 6 - Visualization of the L2/3 model neuron's morphology. (A) Morphology colorcoded according to type of morphological structure: soma (black), axon (blue), apical dendrites (purple), or basal dendrites (red). (B) Crop of region around soma (black circle), showing apical and basal dendrites. (C) Dendrogram of the morphology, indicating length of segments in vertical axis. Diameters have been scaled by a factor of 3 for visibility.

\section{L2/3 neuron morphology}
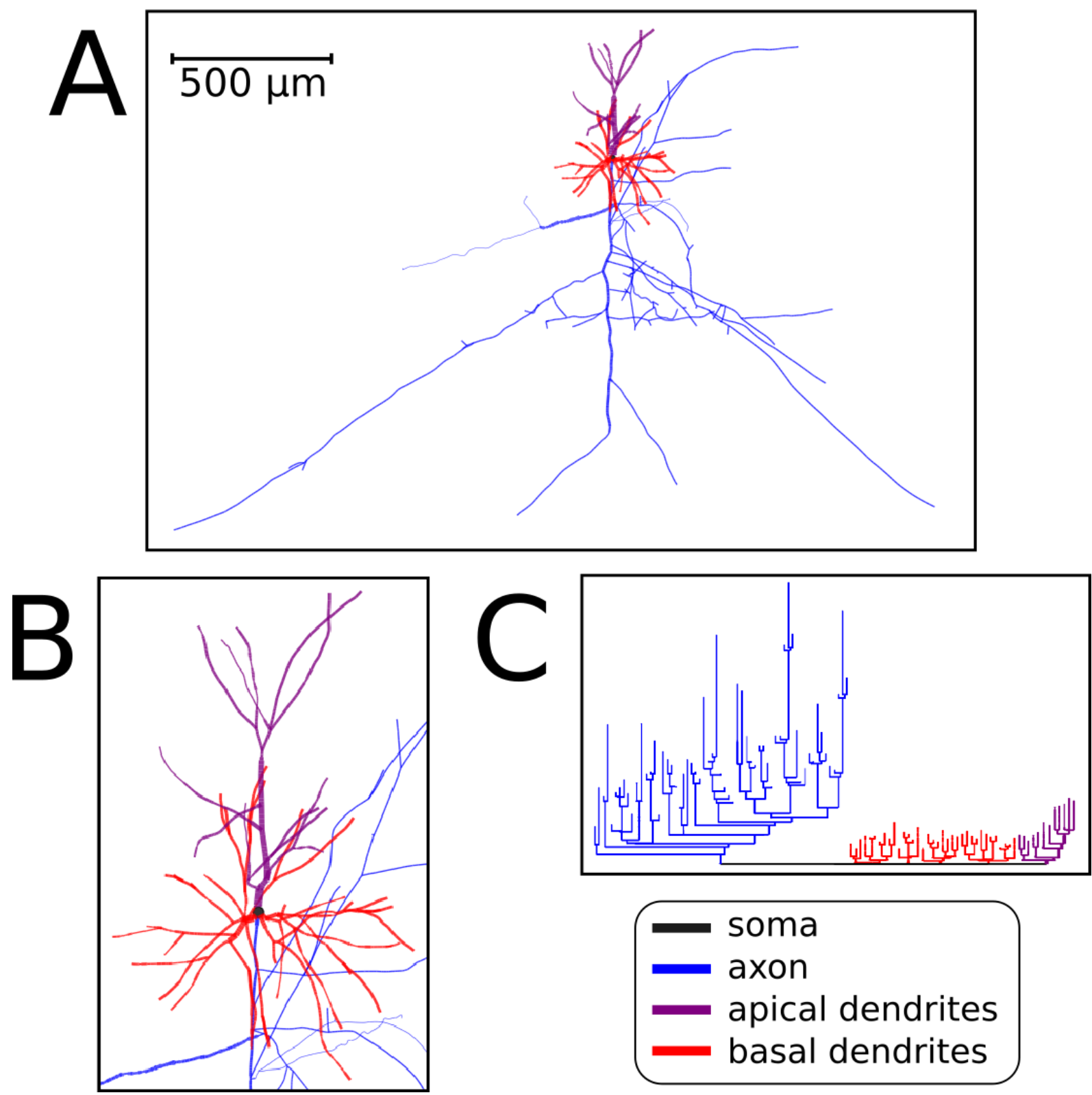

\subsubsection{Simulation of electric field on cortex surface}

The static component of the electric field induced by a TMS pulse of base intensity (1.0 $\mathrm{A} / \mu \mathrm{s}$ ) in the head of a subject (Figure 8) was calculated on MRI-segmented head tissue meshes using SimNIBS 2.1.2 (Figure 7). The meshes were extracted from an example 
data set of a healthy subject, distributed along with SimNIBS (WINDHOFF; OPITZ; THIELSCHER, 2011), containing gray matter, white matter, cerebrospinal fluid, skull and scalp tissues. Prior to the field calculations, anisotropic conductivity, derived from DTI data, was assigned for the white matter tissue with the volume normalized mapping method.

Figure 7 - Example of estimative of electric field induced by the coil (i.e., dA/dt) in different MRI-segmented subject meshes, calculated in SimNIBS. (A) dA/dt in scalp mesh. (B) dA/dt in grey matter mesh. Yellow sphere indicates coil position (at $4 \mathrm{~mm}$ from skin), with red and green axes indicating the coil plane (with green axis being along the coil handle) and blue axis being orthogonal to that plane. (C) Illustration of axes convention followed by SimNIBS, with x, y, $\mathrm{z}$ axes being indicated in A and B by the red, green, and blue axes, respectively. C: adapted from SimNIBS 2.1.2 documentation.
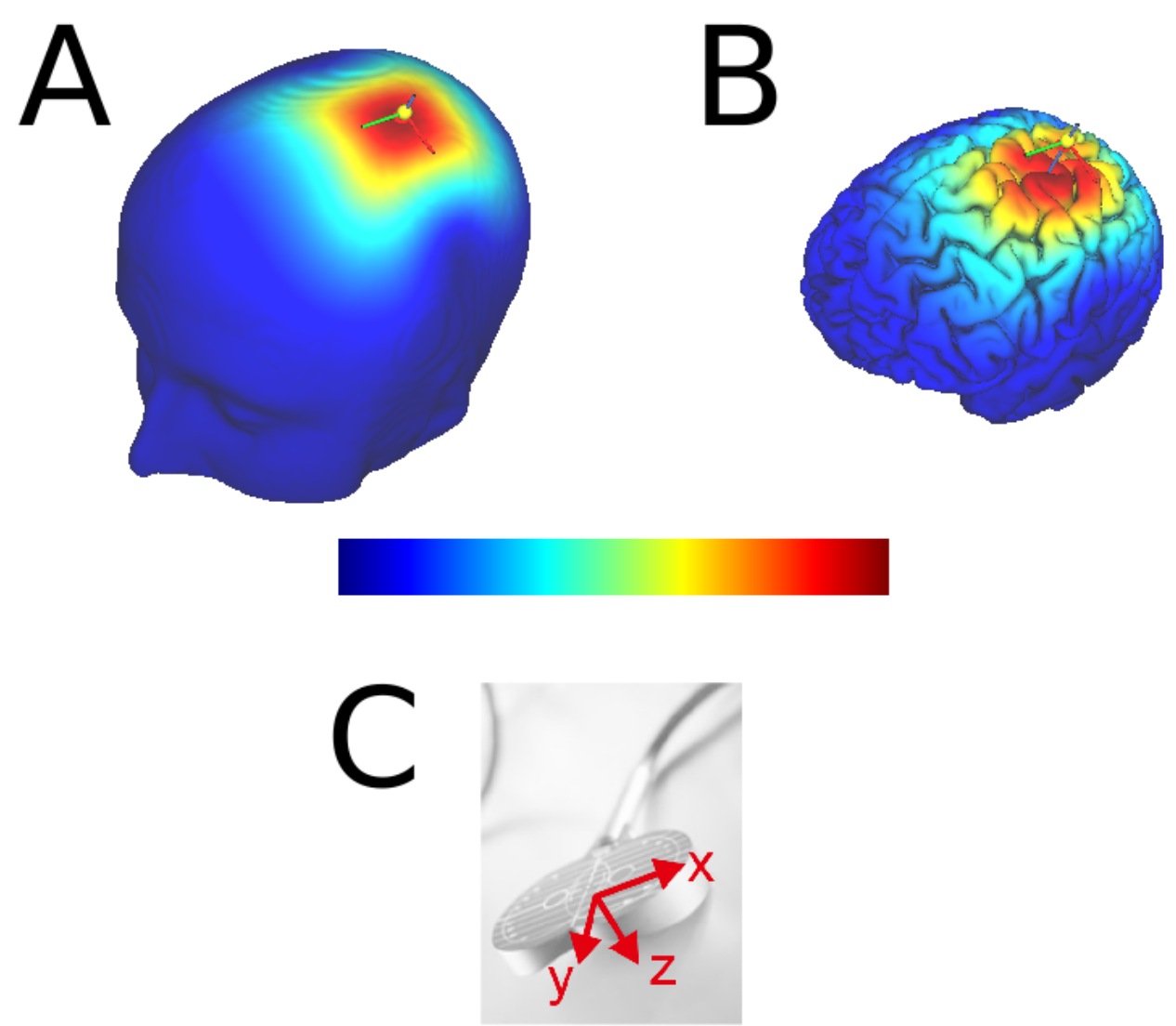
Figure 8 - Pseudocolor visualization of the values of electric field magnitude in a gray matter mesh at the standard stimulation intensity (i.e., $1.0 \mathrm{~A} /$ microseconds), calculated using the SimNIBS software package. Colors indicate values of magnitude of total electric field $(\mathrm{V} / \mathrm{m})$, according to the color bar. Red points at hand knob indicate centers of mesh elements of the motor cortex region, selected for positioning neurons.

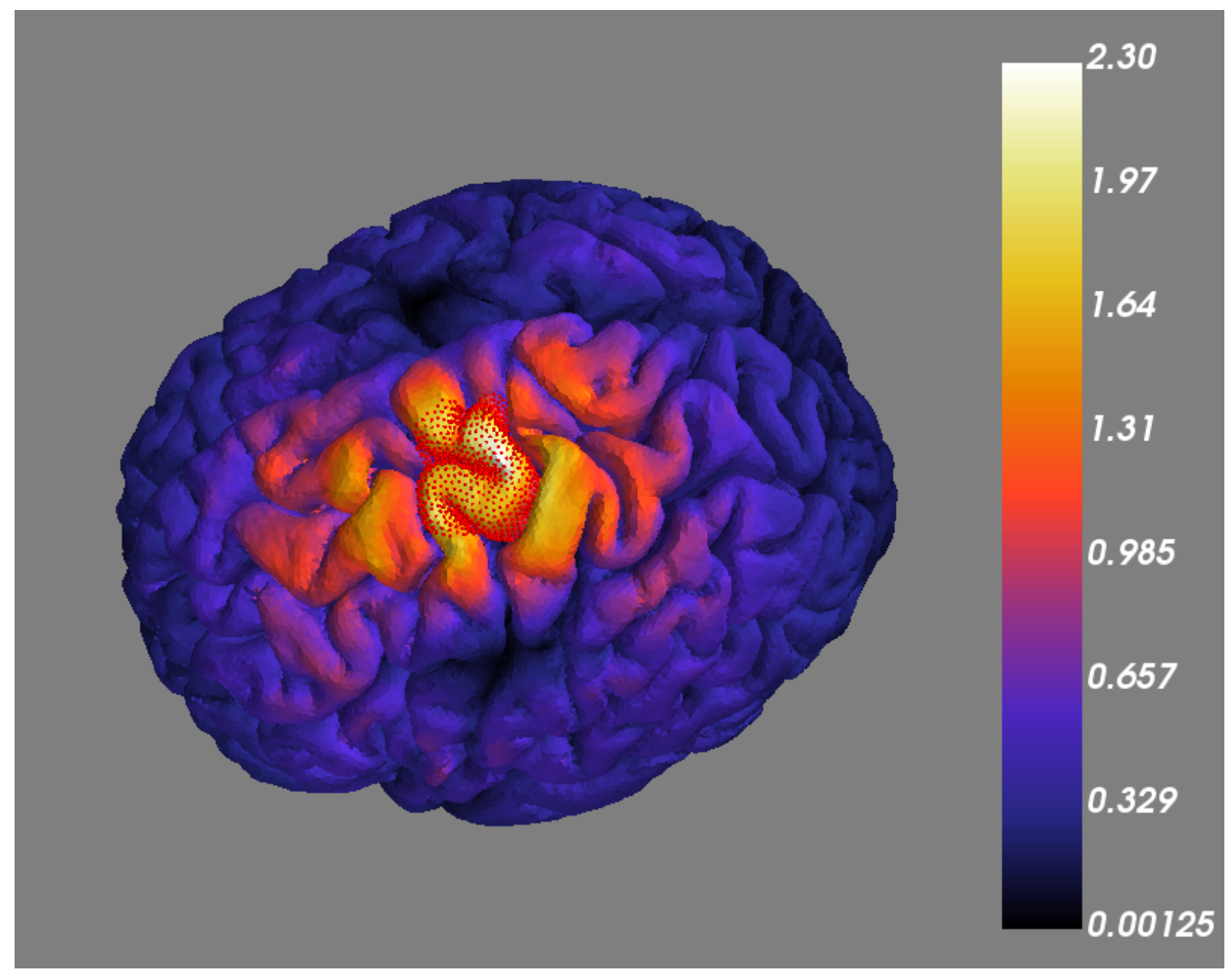

\subsubsection{Simulation of current waveform in the TMS coil}

A monophasic TMS pulse with a duration of approximately $60 \mu$ s was used for all simulations and calculations of thresholds (Figure 9). The monophasic waveform was modeled as an underdamped current of an RLC circuit (PASHUT et al., 2011). 
Figure 9 - Current $I(t)$ (left) used in the model as a simulation of a monophasic current passing through a TMS coil; and its time derivative $\frac{d I}{d t}$ (right) which corresponds to the normalized time course of the coil-generated electric field.
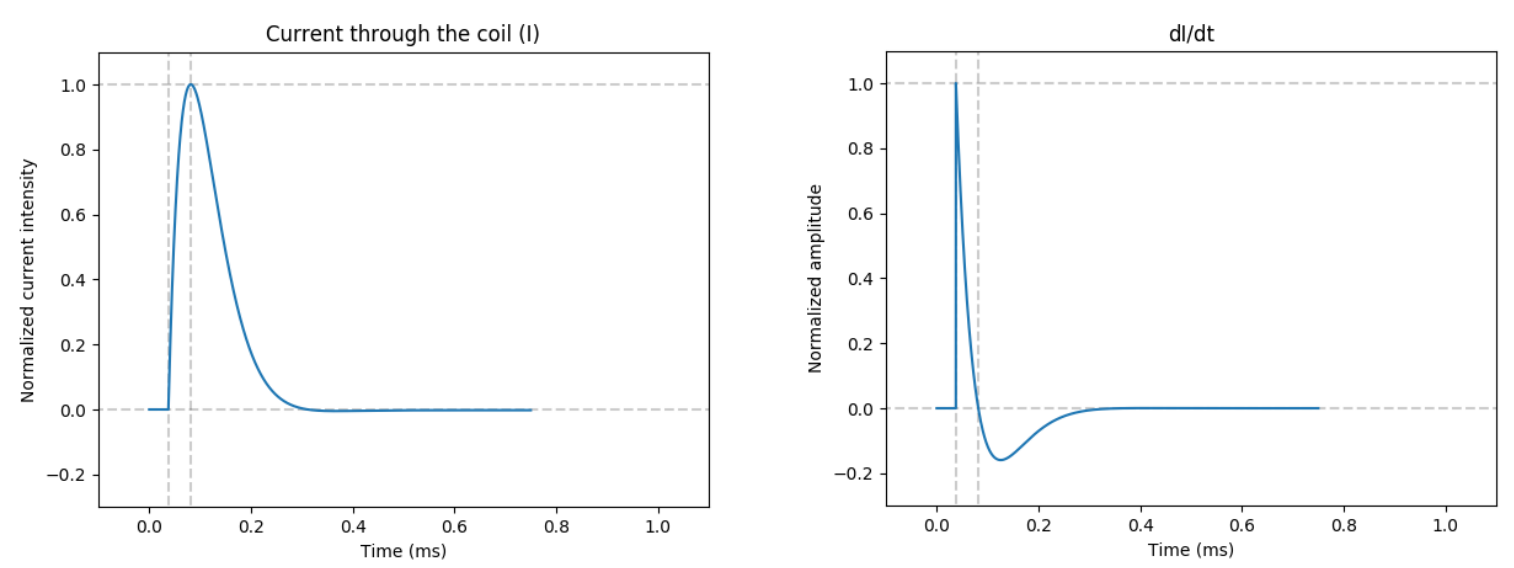

\subsubsection{Transforming neuron morphologies to follow cor- tical folding}

To create a population of neurons with positions and orientations following the folding of human cortical layers, 3D points representing the center of the neurons' somas were generated with a custom algorithm that estimates cortical thickness based on a triangular mesh of the surface of the motor cortex.

The motor cortex region within the gray matter mesh was identified by sight and then manually extracted. In the custom algorithm, each model neuron is associated to an identifying numerical index, which is also assigned to each triangular element of the motor cortex submesh, so that the total number of neurons of a population is equivalent to the total number of mesh elements of the motor cortex submesh. Cortical thickness is estimated by extending inwards the normal vector of each mesh triangular element (which conventionally points outwards), and then finding the point at which the vector intersects the white matter mesh using the Intersect WithLine function of the vtkOBBTree VTK class. The thickness is then defined as the distance between the original position of the normal vector and the determined intersection point, with estimated thicknesses greater than an upper limit in micrometers being replaced by a constant value to remove problematic points. Then, the distance of a soma center from the cortex surface is calculated as a specific fraction (i.e., relative depth) of the estimated cortical thickness. Finally, neurons of a specific cortical layer are positioned, keeping a constant relative distance from the cortex surface. A specific value of relative depth was assigned to each of the two modeled cortical layers: L2/3, 0.42; L5, 0.61.

Each neuron model was rotated such that its somatodendritic axis was parallel to the normal vector of the triangular elements of the gray matter mesh and pointing in the same 
direction, imitating the columnar arrangement of neurons in the human cerebral cortex. Subsequently, each neuron was randomly rotated around its own somatodendritic axis to prevent a single direction of applied electric field to be biased due to a purely coincidental arrangement of neuron morphologies. This random rotation allows the quantitative comparison of tangential (i.e., mostly aligned with axon collaterals) and radial components (i.e., aligned with somatodendritic axis) of electric field with no specific direction of axon collaterals being erroneously favoured.

\subsubsection{Coupling of the electric field to the neuron mod- els}

NEURON's built-in extracellular mechanism simulates the excitation effects of extracellular fields (e.g., electric fields) over neurons by applying the spatial component of the external field to the cable equation (CARNEVALE, 2006). Within the NEURON environment, the e_extracellular variable represents the electric potential value at one extracellular space node immediately over the simulated neuronal membrane, assuming the conductivity is constant throughout the extracellular space (APPUKUTTAN; BRAIN; MANCHANDA, 2017). To simulate the time course of the electric field induced during TMS at each point of the extracellular space, the e_extracellular variable was made to follow the time course of the derivative of the current flowing through the coil $\left(\frac{d I}{d t}\right)$ by using NEURON's built-in play function, which sets the time course of the extracellular potential as a boundary condition to the cable equation (LINDÉN et al., 2014) (HAGEN et al., 2019).

Extracellular quasipotentials were calculated at each compartment center of the corresponding cell by integration of the induced electric field (Equation 3.2) (ABERRA et al., 2020):

$$
\psi_{c}=\psi_{p}-\int \mathbf{E} \cdot d \mathbf{s} \approx \psi_{p}-\frac{\mathbf{E}_{c}+\mathbf{E}_{p}}{2} \cdot \mathbf{s}_{p c}
$$

where $\psi_{c}$ and $\psi_{p}$ indicate the quasipotential of the current and previous compartment, respectively; E, the electric field vector; s, the displacement vector. The soma compartment was used as reference value and was assigned a quasipotential of 0 (ABERRA et al., 2020).

The spatial component of the E-field, expressed as quasipotentials (Figure 10), was multiplied by the normalized time course of the E-field, which is equivalent to the time course of the derivative of the current in the coil. The time course was previously normalized to an amplitude of 1 for its use in the scaling of the quasipotentials. 
Figure 10 - Example of quasipotentials calculated for a L2/3 neuron by numerical integration of the electric field under quasistatic approximation. The represented neuron morphology is composed of points representing the position of each compartment of the neuron. The points are color-coded by magnitude of the quasipotential, given in $\mathrm{mV}$.

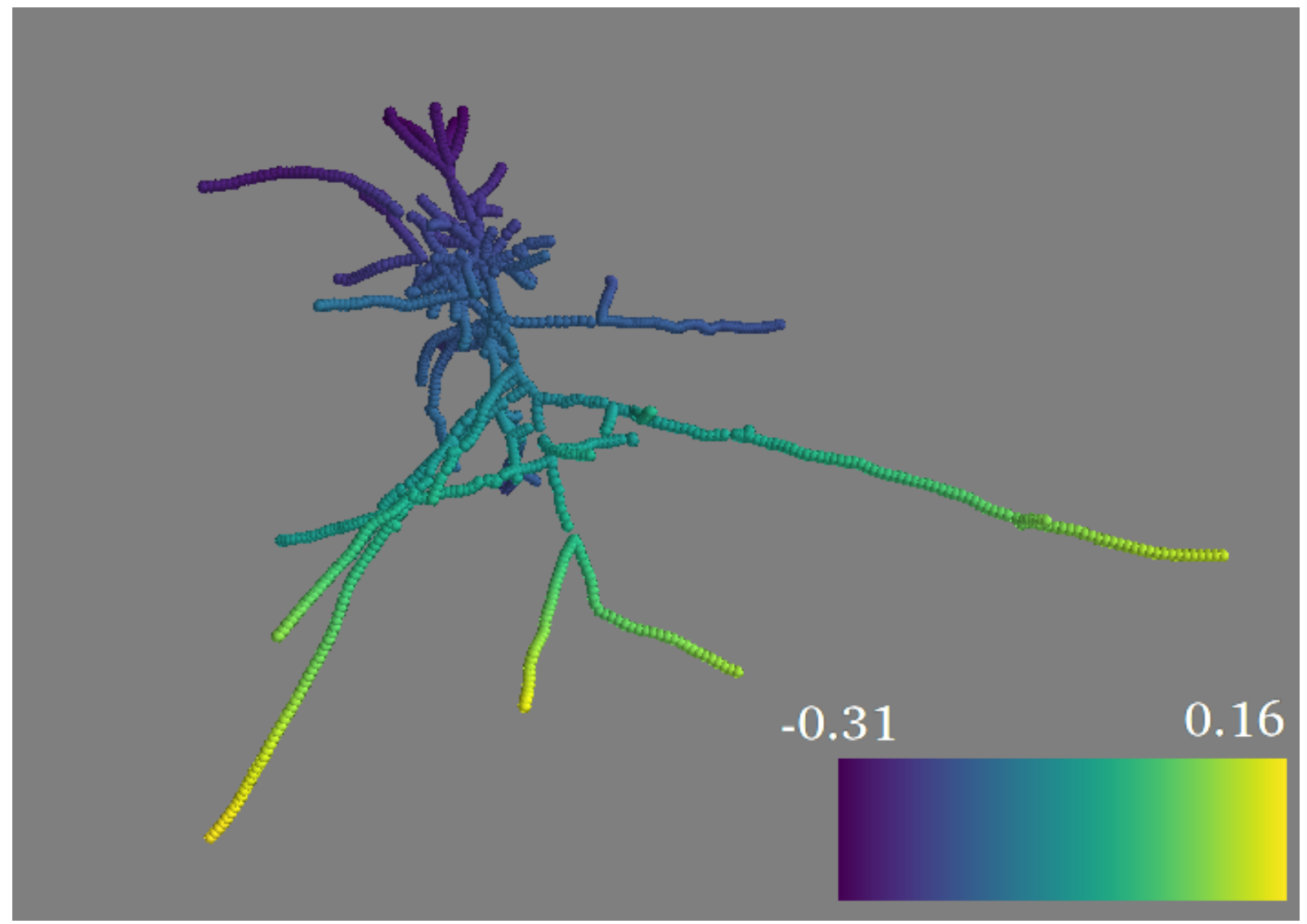

\subsubsection{Determination of excitation thresholds and ac- tion potential initiation sites}

The activation thresholds of each neuron in the populations were determined with a binary search algorithm operating over the 0 and $1500 \mathrm{~A} / \mu$ s range. A neuron was considered as having activated if the membrane potential crossed $0 \mathrm{mV}$ at 3 or more compartments (ABERRA et al., 2020).

Coil orientation was incremented in steps of $45^{\circ}$ with start at $0^{\circ}$ (perpendicular to central sulcus and in PA direction), resulting in a total of 8 orientations: $0^{\circ}, 45^{\circ}, 90^{\circ}$, $135^{\circ}, 180^{\circ}, 225^{\circ}, 270^{\circ}$, and $315^{\circ}$ (Figure 11). Excitation thresholds for two populations of neurons, at each of the two simulated cortical layers (L2/3 and L5), were calculated for each coil orientation.

Sites of action potential initiation were defined as the compartments at which membrane potential crosses $0 \mathrm{mV}$ for the first time in the entire time frame of simulation 
of the corresponding neuron; i.e., time of activation of a neuron was defined as the first time any compartment of the neuron crossed $0 \mathrm{mV}$ and then sites of action potential initiation were defined as being all compartments that crossed $0 \mathrm{mV}$ at that time. For each neuron, a matrix representing the time course of the membrane potential at each of its compartments was used for the calculations (Figure 12).

Figure 11 - Coil orientations (with coil positioned over the motor cortex) used for calculating estimates of electric field and, subsequently, excitation thresholds. Different angles of visualization are shown. Arrows in green show each coil handle orientation. Blue arrow is normal to the coil plane. (A) Anteroposterior view of gray matter mesh. (B) Top-down view of coil orientations with respect to gray matter mesh. The pseudocolor visualization in the gray matter mesh is related only to height in $\mathrm{z}$ axis (representing neither electric field nor potential) and was used only for visibility.
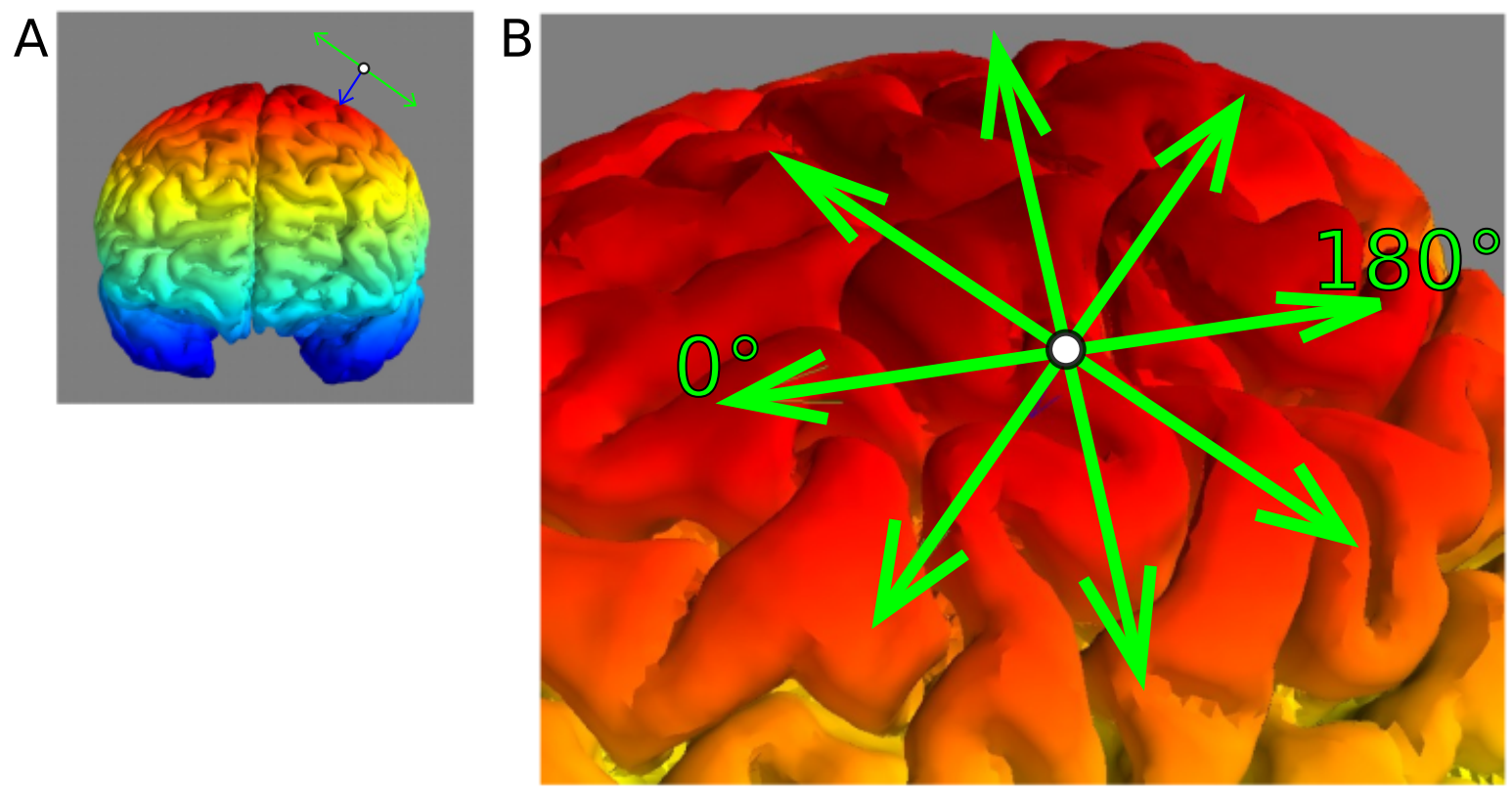
Figure 12 - Example of 2D matrix (visualized in pseudocolor) representing the time course of the membrane potential at all compartments of a single neuron. Red arrow indicates compartment considered as action potential initiation site. Horizontal axis indicates simulation time steps (each with $0.025 \mathrm{~ms}$ ). Vertical axis indicates the indices of the compartments of the neuron.

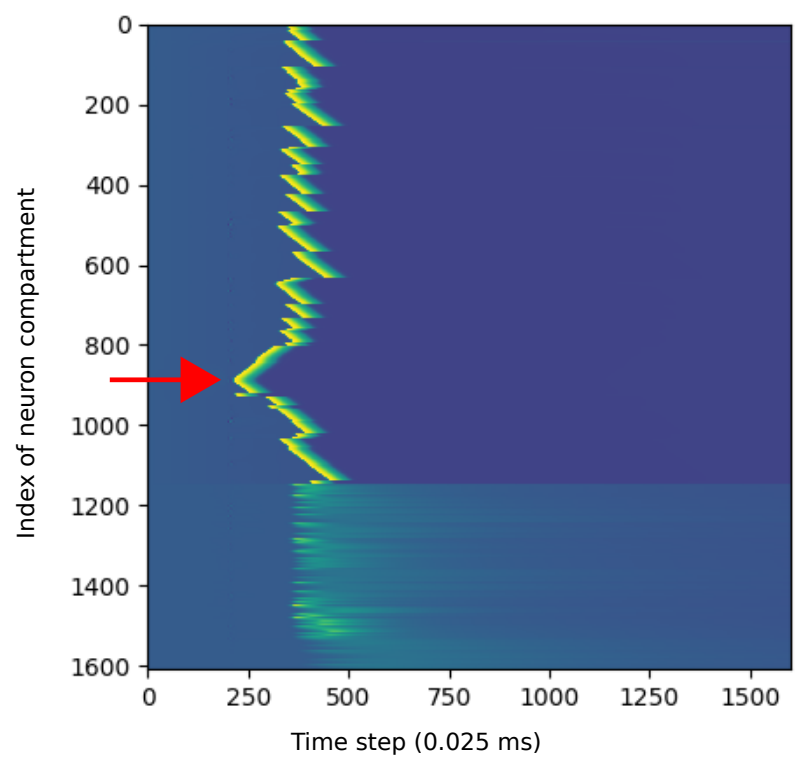

\subsection{Neurons in a feedforward network}

A feedforward network was implemented, representing a motor cortex circuit of a population of 150 L2/3 neurons projecting onto a single L5 neuron. This network was simulated repeatedly (12 times) and the outputs of the L5 neuron across all iterations each representing the response of a single axon in the corticospinal tract - were used to compose a simulated epidural response to a TMS pulse applied over the motor cortex (SCHAWORONKOW; TRIESCH, 2017). This feedforward arrangement is based on the assumption that L2/3 and L5 pyramidal neurons compose a circuit which processes afferent information and then communicates with cortical and subcortical areas (KANEKO, 2013), and on the success of previous feedforward computational models of explaining properties of D- and I-waves (ESSER; HILL; TONONI, 2005) (RUSU et al., 2014).

Four types of synaptic receptors were simulated: two excitatory (voltage-independent AMPA and voltage-dependent NMDA, both ionotropic), and two inhibitory (ionotropic $\mathrm{GABA}_{A}$ and metabotropic $\mathrm{GABA}_{B}$ ). The time constants and reversal potentials for each receptor type are given in Table 1 (RUSU et al., 2014).

L2/3 neurons were categorized by synapse projection types (with each L2/3 neuron having only one synapse type) and followed a proportion of 19:4:5:2 (AMPA, GABA $A$, NMDA and $\mathrm{GABA}_{B}$, respectively) (SCHAWORONKOW; TRIESCH, 2017), with a resulting total proportion of excitatory to inhibitory synapses of 4:1 (RUSU et al., 2014) (BEAULIEU; COLONNIER, 1985). 


\begin{tabular}{l|c|c|c|c}
\hline Receptor type & $\tau_{1}(\mathrm{~ms})$ & $\tau_{2}(\mathrm{~ms})$ & $E_{\text {rev }}(\mathrm{mV})$ & $g_{\text {peak }}(\mu \mathrm{S})$ \\
\hline AMPA & 0.2 & 1.7 & 0 & 0.2 \\
NMDA & 2.0 & 26.0 & 0 & 0.03 \\
GABA $_{A}$ & 0.3 & 2.5 & -70 & 0.5 \\
GABA $_{B}$ & 45.2 & 175.16 & -70 & 0.05 \\
\hline
\end{tabular}

Table 1 - Values of time constants, reversal potential and peak conductivity used for each simulated synaptic receptor type.

In the cerebral cortex, L2/3 pyramidal neurons mainly project excitatory synapses onto the dendritic trees of L5 pyramidal neurons. However, in this network model, L2/3 pyramidal neurons were used for the inhibitory neuronal populations on the basis that L2/3 neurons can also cause inhibition on L5 neurons by indirectly activating GABAergic interneurons (QUIQUEMPOIX et al., 2018).

The geometric transformations applied to the neuronal morphologies in the first part of this work were applied to the neurons in the network, with the specific positions of each neuron being randomized at each run, such that the neurons vary their positions within the respective layer of the motor cortex.

\subsubsection{Modifications to L5 neuron model}

The axonal compartments of original L5 cells published by the Blue Brain Project (MARKRAM et al., 2015) could not achieve I-wave frequencies of $600 \mathrm{~Hz}$ (equivalent to 6 spikes per $10 \mathrm{~ms}$ ), achieving only close to $200 \mathrm{~Hz}$ with cell body current injections of up to $40 \mathrm{nA}$. Therefore, the biophysics of the L5 neuron were modified - while keeping the original morphology - to have simplified ion channel kinetics as modeled by Rusu et al. (RUSU et al., 2014) (Figure 13). The geometric, but not the biophysical, modifications by Aberra et al. (ABERRA et al., 2020) were kept. The ion channel kinetics of L2/3 neurons were kept unchanged. The L5 neuron's axonal compartments featured a delayed-rectifier potassium current $I_{K_{D R}}$.

\subsubsection{Synapses projecting onto L5 neuron}

The synapses from L2/3 neurons to the L5 neuron had weights randomized from a lognormal distribution, with the base normal distribution having a mean of -1.3 for excitatory neurons and -2.6 for inhibitory neurons (SCHAWORONKOW; TRIESCH, 2017), and a standard deviation of 0.5 for both types. Each connection from a L2/3 neuron to the L5 neuron contained 3 synapses, based on the minimum number of synapses seen for glutamatergic connections in neocortex (3 to 12) (MARKRAM, 2010), and were equal among connections for the purpose of balancing the number of excitatory and inhibitory projections onto the L5 neuron dendritic tree. Synapses were placed on the dendritic tree of the 
Figure 13 - Time course of membrane potential at axon initial segment of L5 neuron with modified biophysics. A current of $19 \mathrm{nA}$ was injected at cell body during the interval of 50 and $100 \mathrm{~ms}$. Between intervals 0 to $50 \mathrm{~ms}$, and 100 to $150 \mathrm{~ms}$, no stimulus was applied. In the stimulus period of $50 \mathrm{~ms}$, the cell achieved 32 action potentials ( 0.64 per $\mathrm{ms}$, or 640 per second). The modified cell, therefore, was capable of achieving I-wave frequencies (around $600 \mathrm{~Hz}$ ). Horizontal axis indicates time, in ms. Vertical axis indicates membrane potential, in $\mathrm{mV}$.

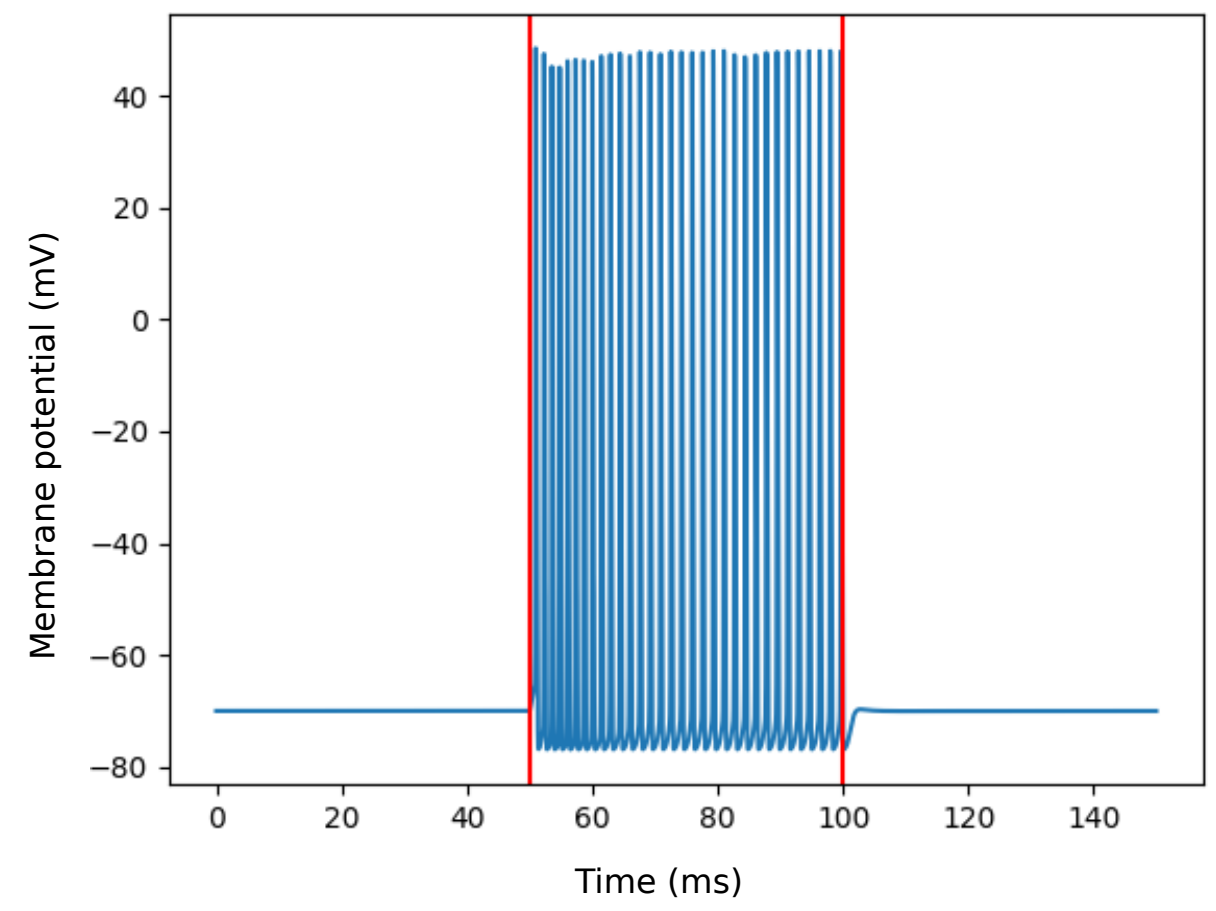

L5 neuron (basal and apical dendrites), following a uniform distribution. Transmission delays were proportional to distance between the neurons with a factor of $5.5 \cdot 10^{-5}$.

For each L2/3 neuron, the spike detector that activates synapses (i.e., the spike threshold of a NEURON "NetCon" object) was attached to a single, randomly chosen axonal terminal - instead of the default setting of placement at a soma. This was made to test the hypothesis of transsynaptic activation.

The synapses featured short-term depression. The weights were modulated by a depression factor $D$, which starts with a value of 1.0 and is multiplied by a factor of 0.5 for each presynaptic action potential to capture the depressive effect on the weights (RUSU et al., 2014). With no terminal activation, D recovered exponentially to its initial value, with a time constant $\tau_{D}$ of $200 \mathrm{~ms}$ :

$$
\dot{D}=\frac{1-D}{\tau_{D}}
$$




\subsubsection{Poisson spike trains on L2/3 neurons}

For some simulations, L2/3 neurons were stimulated with inhomogeneous Poisson spike trains arriving from 70 artificial neurons throughout the network simulation; the synapse weights were 1.0. The rates of spike trains were $2.0 \mathrm{~Hz}$ on excitatory neurons and 4.0 $\mathrm{Hz}$ on inhibitory neurons, being modulated with a sine wave of $10 \mathrm{~Hz}$ (i.e., the rate of oscillations corresponding to the $\mu$ rhythm of motor cortex).

\subsubsection{Simulating epidural recordings after TMS pulse}

The simulated epidural response is calculated by averaging, across 12 repeated simulations, the time courses of membrane potential at a compartment of the main axon of the L5 neuron. Afterwards, they are convolved with a Gaussian kernel to account for different transmission delays in axons of L5 neurons within the corticospinal tract (SCHAWORONKOW; TRIESCH, 2017). 



\section{Results}

\subsection{Synaptically isolated neurons}

\subsubsection{Sites of action potential initiation}

\subsubsection{Stimulated neural elements}

Activation occured at axons. Across all coil orientations and cell types, immediate depolarization of cell somas due to TMS pulse at excitation threshold intensity was insufficient for reaching action potential threshold before other compartments; all direct activation occurred at axonal compartments (Figure 15).

This agrees with experimental measurements which show higher membrane time constants for cell bodies when compared with myelinated axons (NOWAK; BULLIER, 1998), and recent computational simulations using the same neuron models as the current study (ABERRA et al., 2020). Older computational studies have indicated cell bodies as the main targets of activation (SEO et al., 2017), but have been pointed for implementation errors (ABERRA et al., 2020).

Activation was always axonal for all orientations. For example, at coil orientation $0^{\circ}$ and for a population of $2138 \mathrm{~L} 2 / 3$ neurons, nodal sites crossed $0 \mathrm{mV}$ first for 2669 times, and myelinated sites, 6379 times, with all other types of compartment (e.g., basal dendrites, apical dendrites, soma and others) never crossing $0 \mathrm{mV}$ for the first time (Figure 14). Across all L2/3 neurons at a single orientation, hundreds of unique sites were activated, but counting less than 200 .

Sites of excitation were morphological discontinuities, such as terminals and branchings. Across all coil orientations, sites of action potential initiation were almost always terminals, branchings and bendings (Figure 16). 
Figure 14 - Example histogram classifying action potential initiation sites by morphological structure of the neuron (i.e., soma, apical dendrites, basal dendrites, or axonal arbor). Sites of action potential initiation (i.e., the first compartments of the neuron to cross $0 \mathrm{mV}$ after the TMS pulse) were, unanimously, axonal compartments. Compartments belonging to different neuronal structures are labeled 'node', 'myelin' (myelinated parts of axon), 'soma', 'axon' (axon initial segment), 'unmyelin' (unmyelinated parts of axon), 'apic' (apical dendrites), and 'dend' (basal dendrites).

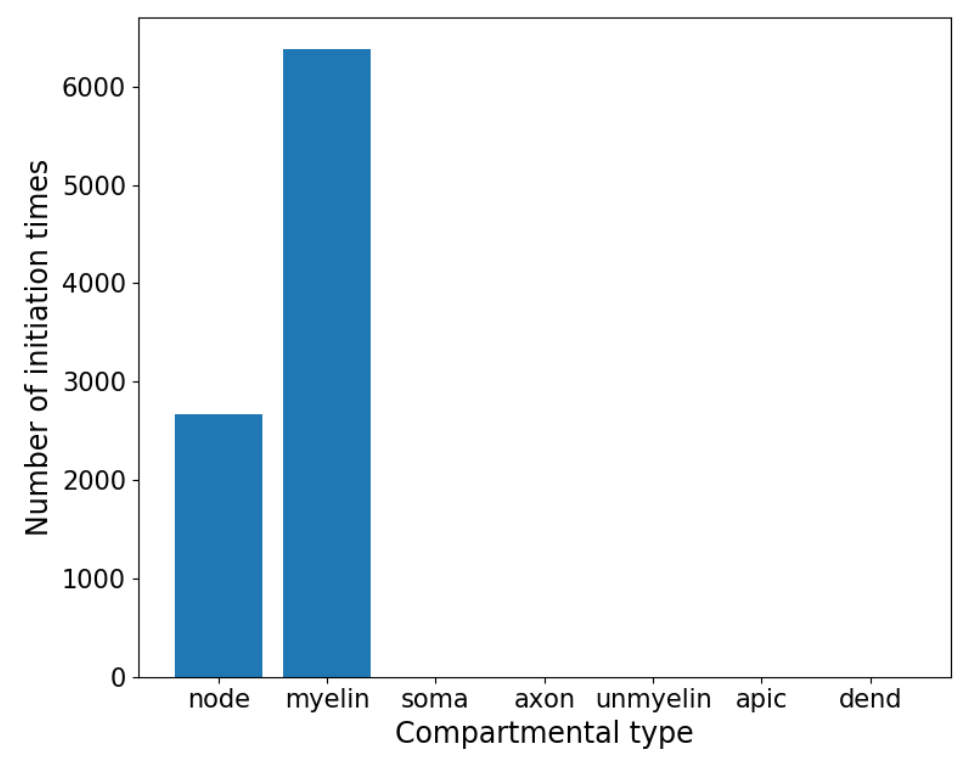

\subsubsection{Alignment of neural elements to electric field vector}

Stimulated axon compartments were mostly aligned with electric field direction. For the purpose of testing the orientation of the stimulated terminals, the same electric field vector was applied to all neurons, disregarding the estimate of the induced electric field in cortex (however, monophasic waveform was mantained). Stimulated compartments showed a tendency of being aligned with the electric field direction when their positions are considered with respect to the neuron soma (Figure 17).

\subsubsection{Excitation thresholds}

\subsubsection{Correlation between electric field components and exci- tation thresholds}

Since each stimulated neuron had a single electric field vector applied to it (because it was assumed to be uniform throughout the neuron), a correlation could be calculated between the neuron excitation threshold (Figure 18) and different components of the electric field vector.

Electric field magnitude was a better predictor of threshold than alignment of the field with cortical columns. Contrary to hypotheses that predict that the 
Figure 15 - Examples of time courses of membrane potential at two different compartments of a L5 neuron: soma and axon terminal. In this example, the axonal terminal was an action potential initiation site. Vertical red line indicates time of application of TMS pulse (i.e., $1.0 \mathrm{~ms}$ ).
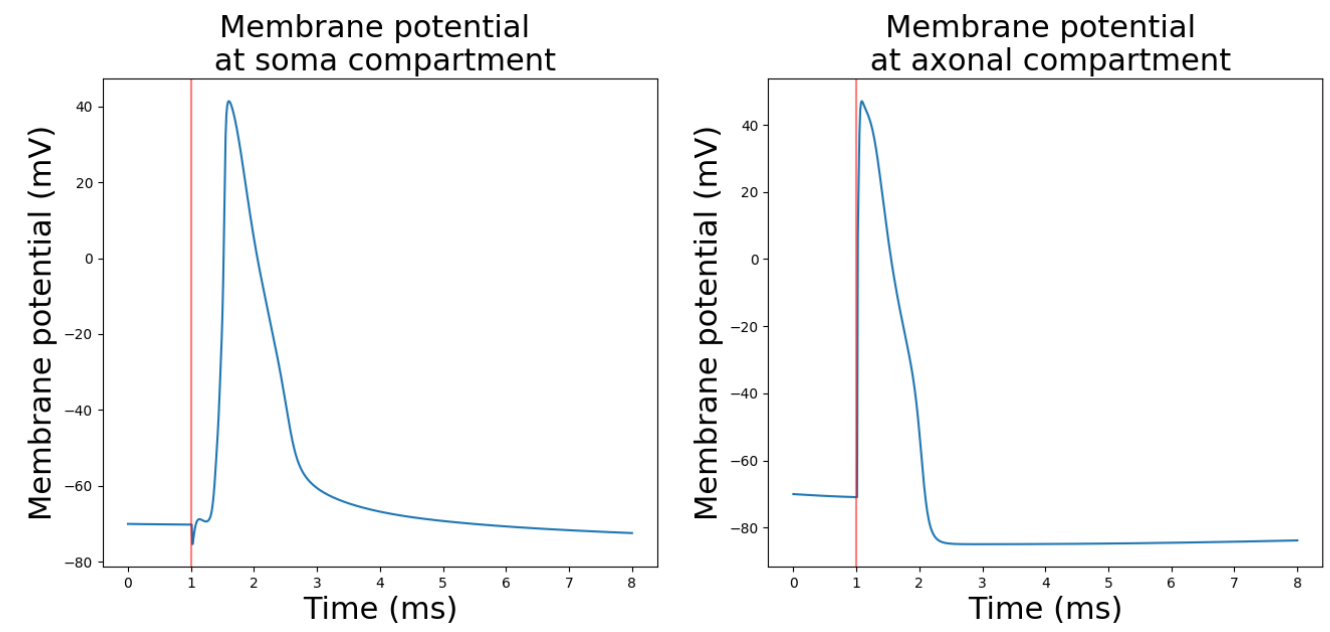

most easily stimulated neurons are the ones aligned with the electric field vector normal to cortical surface (e.g., the "cortical cosine column" hypothesis (FOX et al., 2004)), the electric field magnitude presented a higher correlation with excitation thresholds than the normal electric field component (Figure 19, Figure 20 and Table 2). This agrees with recent computational modeling studies (ABERRA et al., 2020), but disagrees with parts of conclusions of computational studies involving positron emission tomographic (PET) imaging (KRIEG et al., 2015).

\subsubsection{Variation of excitation thresholds with coil orientation}

Mean thresholds were lowest in coil orientations approximately perpendicular to central sulcus. Across all coil orientations, the mean of excitation thresholds were lowest for coil orientation $315^{\circ}$. The highest thresholds for both L2/3 and L5 neurons occurred at $270^{\circ}$, parallel to central sulcus in the mediolateral direction.

\subsubsection{Variation of excitation thresholds with cell type}

L5 neurons had, in general, lower thresholds than L2/3 neurons. For 6 of the 8 simulated coil orientations, the mean threshold was lower for L5 neurons than L2/3 neurons (Figure 21). This indicates that, in general, the TMS pulse stimulates more easily L5 neurons than L2/3 neurons, and excitation thresholds at cortical layers do not depend simply on coil distance.

The lowest mean threshold for any orientation and cell type occurred for L5 neurons at coil angle $0^{\circ}(337.14 \mathrm{~A} / \mu \mathrm{s})$. The lowest mean threshold for L2/3 neurons occurred at $315^{\circ}$ 
Figure 16 - Example of sites of action potential initiation across all L2/3 neurons of a population, for a single coil orientation. The neuron morphology is drawn in white, and each colored point indicates the position of a compartment where an action potential initiated, across all neurons of the population. The points are color-coded (from light blue to red) by number of neurons in the population for which an action potential initiated at that compartment.

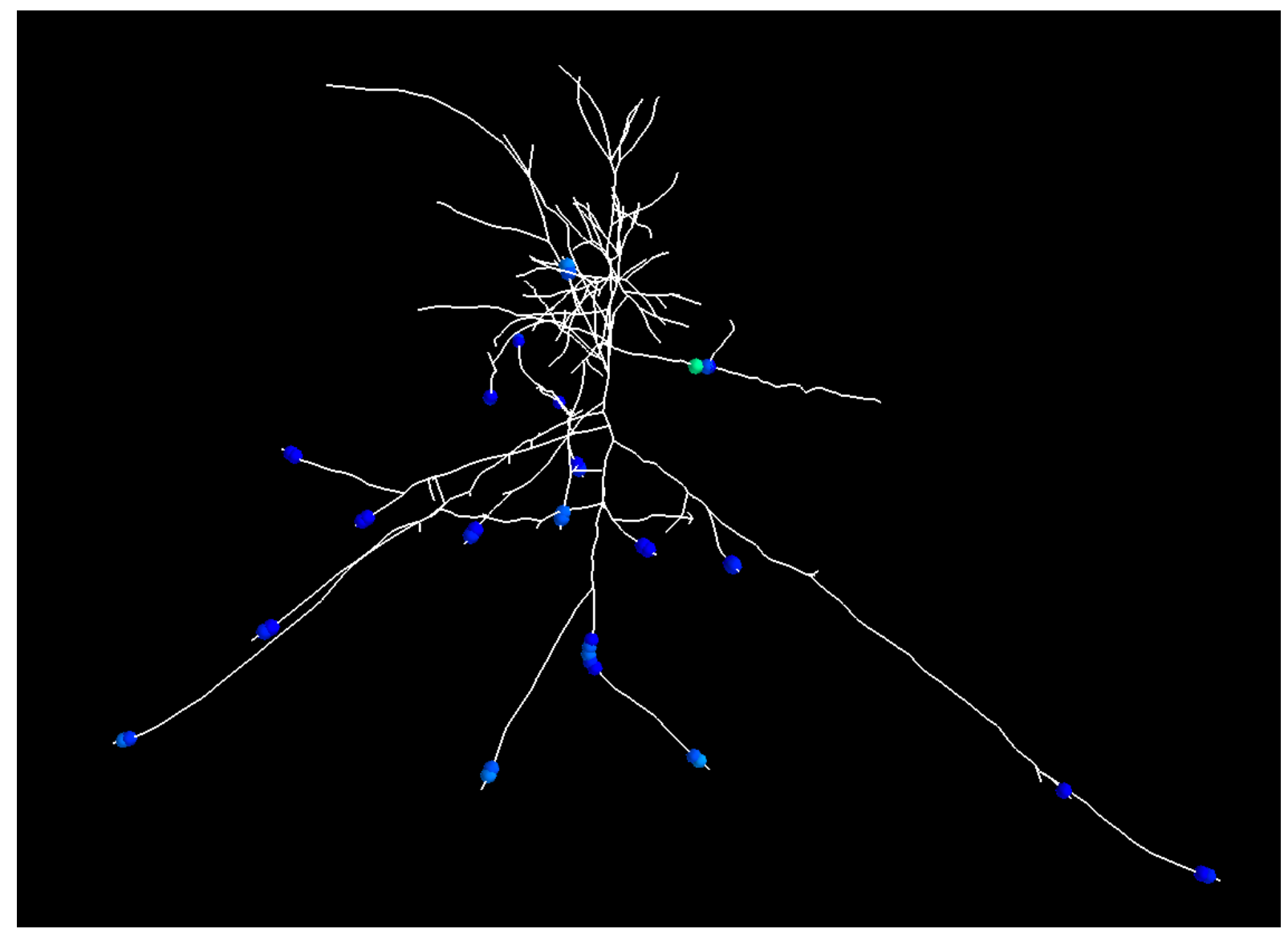

$(349.09 \mathrm{~A} / \mu \mathrm{s})$. For angles parallel to central sulcus $\left(90^{\circ}\right.$ and $\left.270^{\circ}\right)$, the tendency of lowest thresholds was inverted and mean thresholds were higher for L5 than for L2/3 neurons, indicating that the preferentially activated population changes with coil orientation. 
Figure 17 - Direction of an universally uniform electric field (i.e., equal across all neurons, for test purposes) with respect to the stimulated sections. This figure shows a group of neurons in a cross section of the motor cortex mesh. Each red arrow (or vector) points from the soma center to the centroid of 3D points which composed the section where the first action potential initiated (after TMS pulse). The magenta arrow in the middle of the figure represents the uniform electric field vector applied to all neurons. Arrow sizes were normalized for visibility.

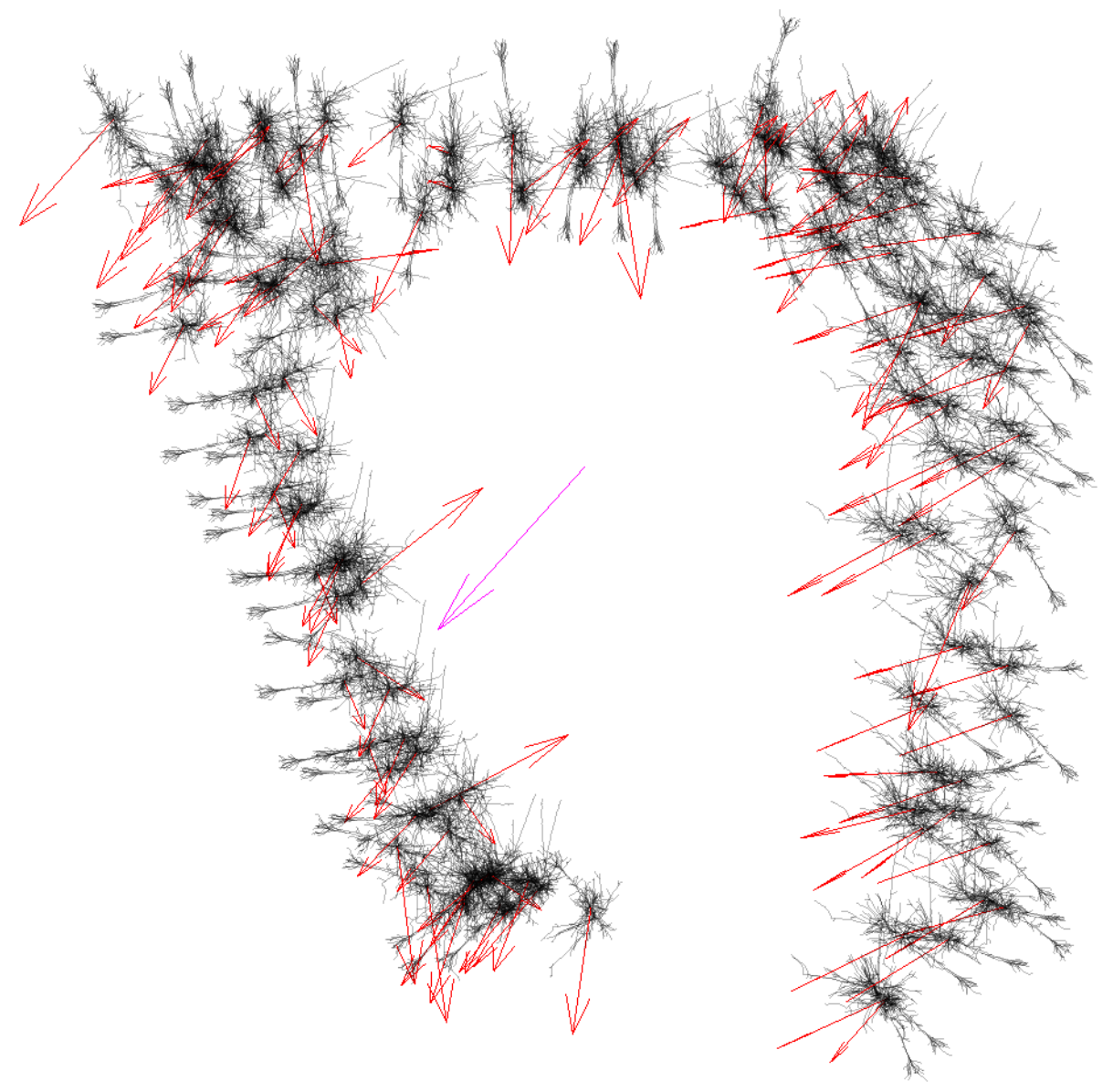


Figure 18 - Histogram of excitation thresholds for L2/3 neurons across all coil orientations. Excitation thresholds follow a log-normal distribution.

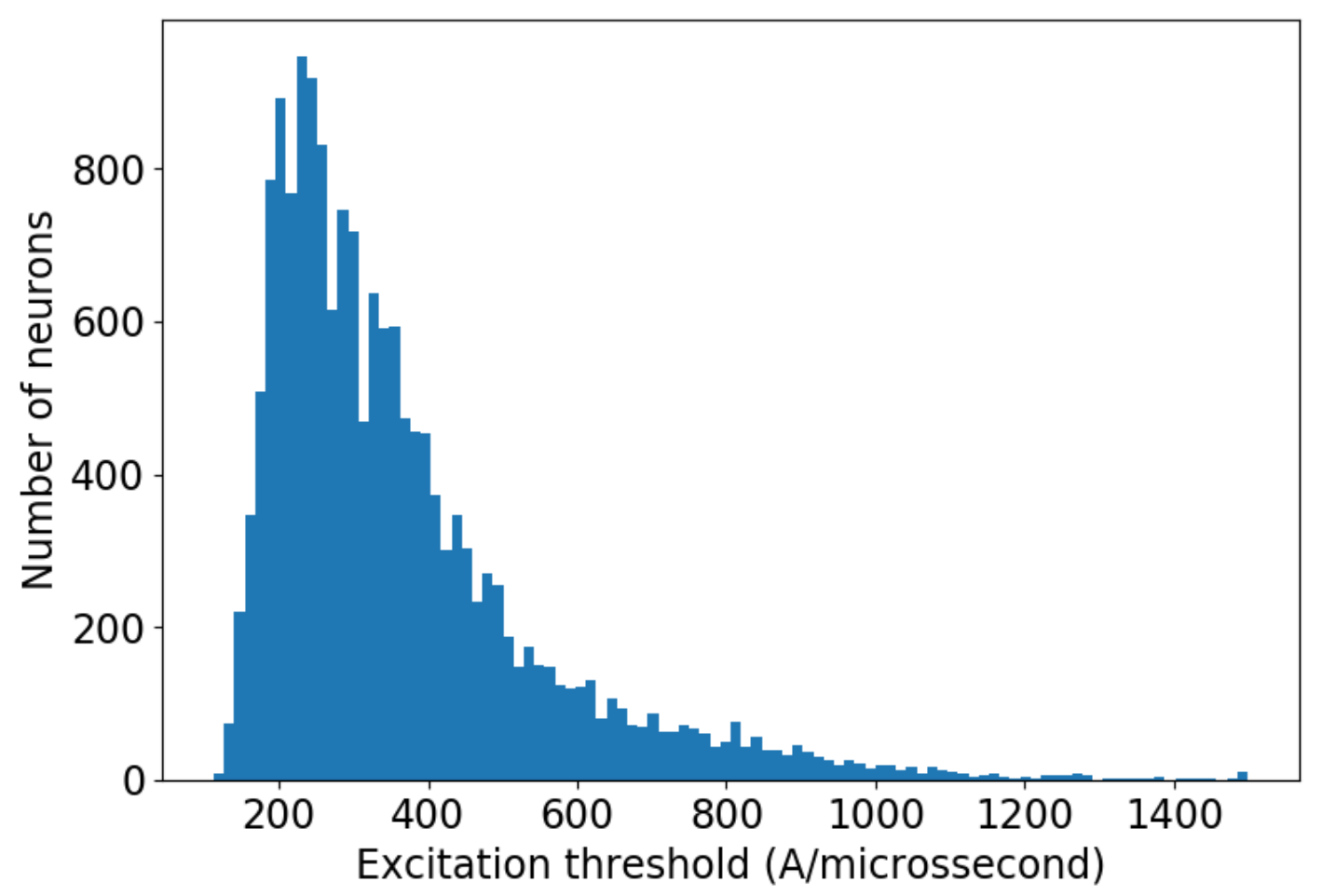

\begin{tabular}{l|c|c|c}
\hline Cell type & Coil angle $\left(^{\circ}\right)$ & Correlation (total E-field) & Correlation (normal E-field) \\
\hline L2/3 & 0 & -0.7668 & -0.3374 \\
& 45 & -0.7387 & -0.1701 \\
& 90 & -0.7616 & -0.2428 \\
& 135 & -0.7636 & -0.3143 \\
& 180 & -0.7834 & -0.3434 \\
& 225 & -0.7726 & -0.1543 \\
& 270 & -0.7621 & -0.2276 \\
& 315 & -0.7695 & -0.2873 \\
& & & -0.5174 \\
& 0 & -0.6849 & -0.2229 \\
& 45 & -0.6986 & -0.2752 \\
& 90 & -0.7483 & -0.3419 \\
& 135 & -0.7225 & -0.4779 \\
& 180 & -0.7394 & -0.2194 \\
& 225 & -0.7220 & -0.2538 \\
& 270 & -0.7464 & -0.3502 \\
& 315 & -0.6995 & \\
\hline
\end{tabular}

Table 2 - Pearson coefficient for correlation between magnitudes of different electric field components and excitation thresholds of each cell type and each coil orientation. All p-values were smaller than $1 \cdot 10^{-10}$. 
Figure 19 - Scatter plot showing correlation between total electric field magnitude (i.e., considering electric field components both perpendicular and parallel to cortical surface) and excitation thresholds for L2/3 neurons at coil angle $0^{\circ}$. This tendency of high inverse correlation was kept across cell types and orientations, with the Pearson correlation coefficient ranging from -0.68 to -0.77 .

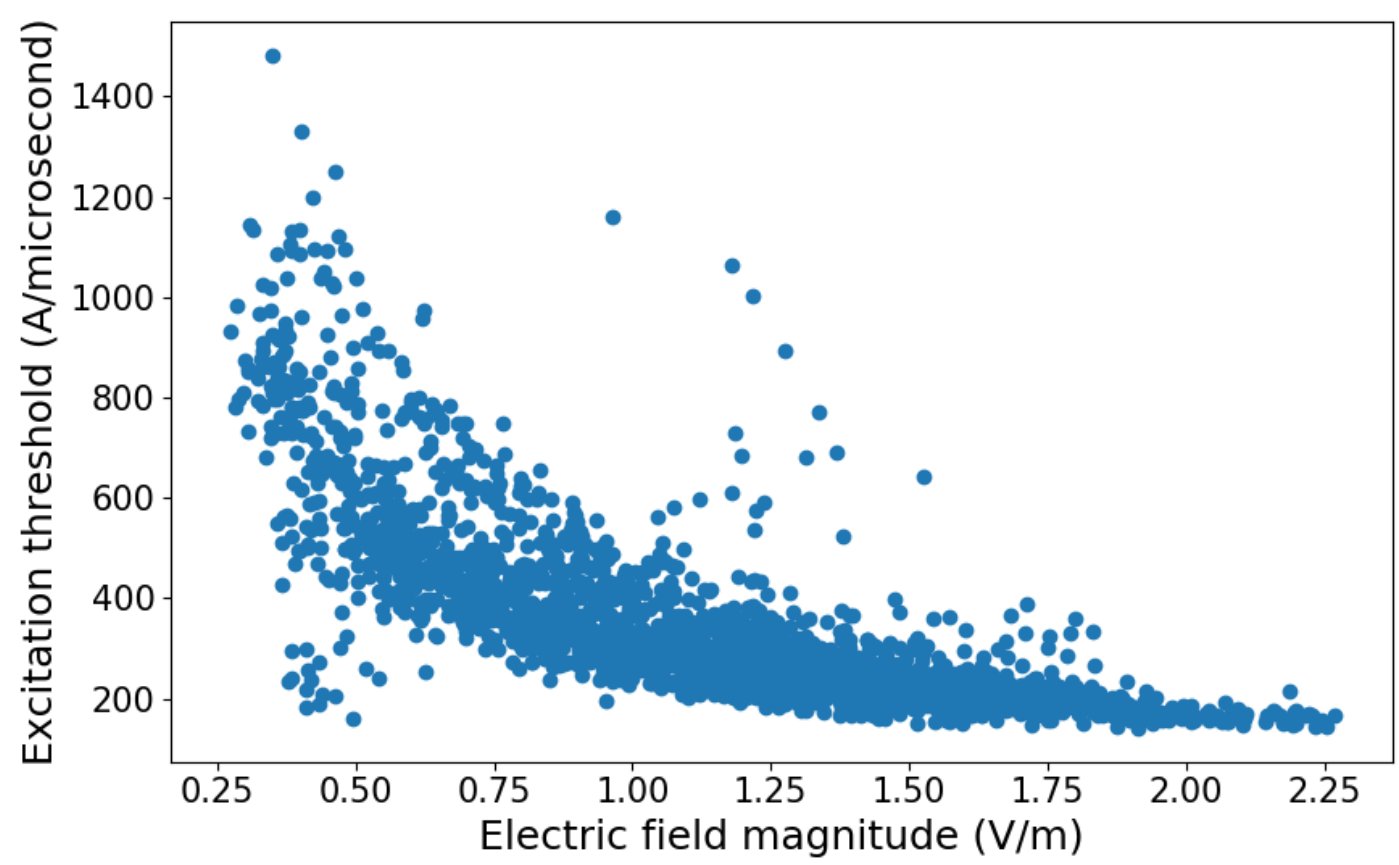

Figure 20 - Scatter plot showing correlation between magnitude of electric field component orthogonal (or normal) to cortical surface and excitation thresholds for L2/3 neurons at coil angle $0^{\circ}$.

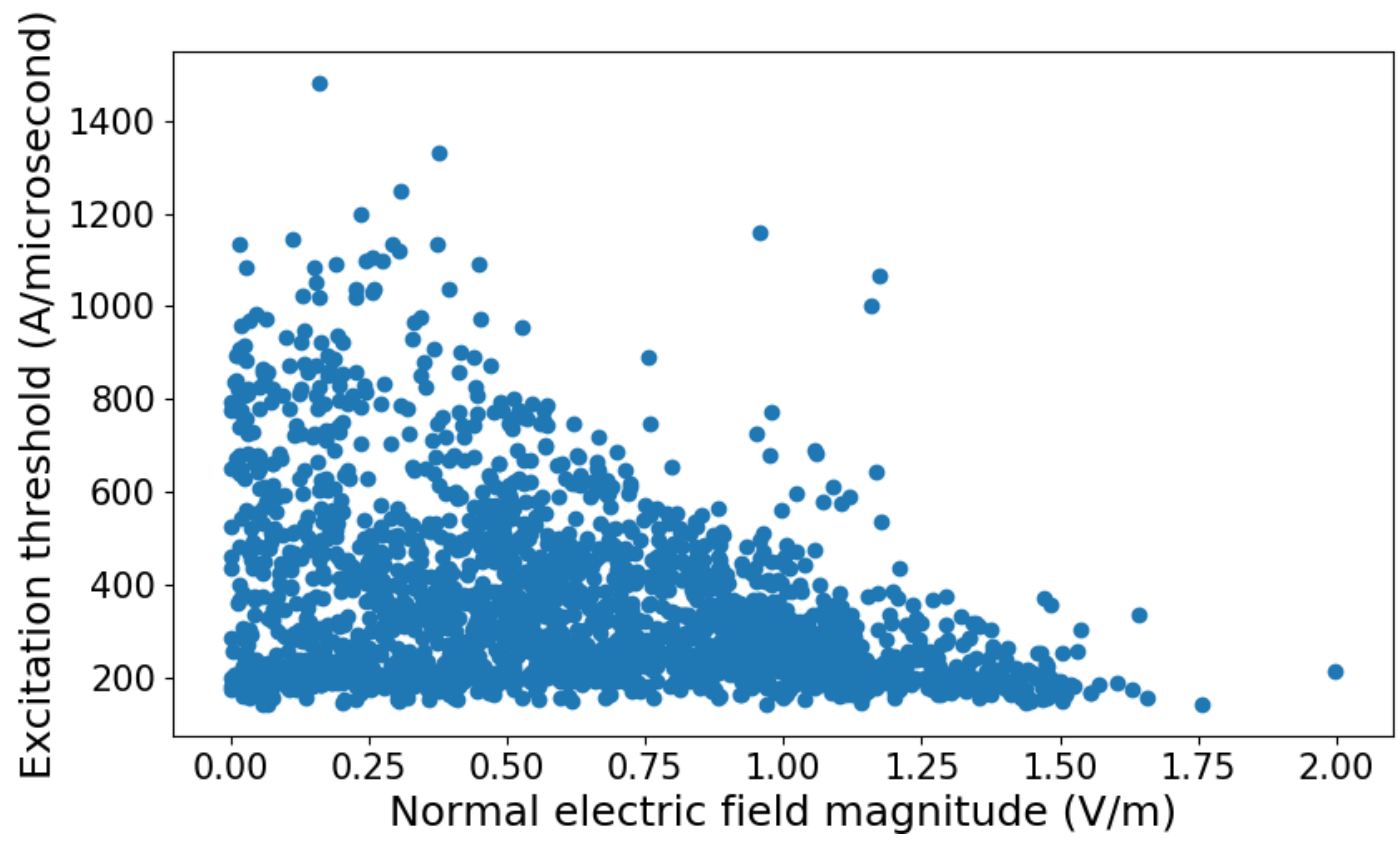


Figure 21 - Variation of means of excitation thresholds according to coil orientation.

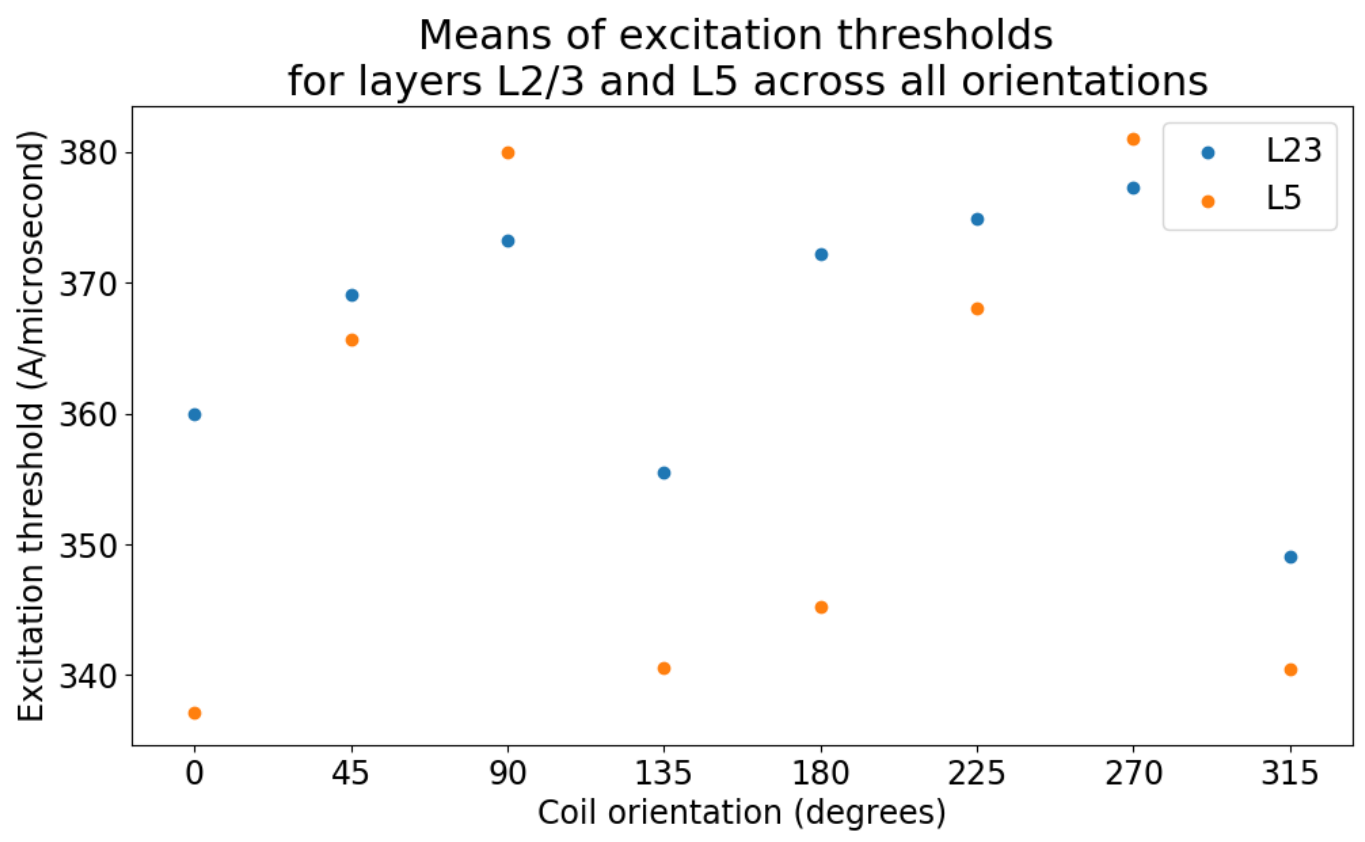

\begin{tabular}{|c|c|c|}
\hline Cell type & Mean & Standard deviation \\
\hline $\mathrm{L} 2 / 3$ & 5.795 & 0.450 \\
\hline L5 & 5.760 & 0.470 \\
\hline Total & 5.777 & 0.461 \\
\hline \multicolumn{2}{|r|}{ T-test } & 6.867 \\
\hline & p-value & $6.676 \cdot 10^{-12}$ \\
\hline
\end{tabular}

Table 3 - Means and standard deviations of the logarithm of excitation thresholds, across all coil orientations; and results of independent sample t-test performed between L2/3 and L5 thresholds. 


\subsection{Feedforward network model of cortical neurons}

\subsubsection{Simulated epidural response}

Simulated epidural response for a network under background activity was calculated for specific coil orientations (Figure 22), with resulting oscillations having amplitudes (dozens of $\mathrm{mV}$ ) and durations (approximately $2 \mathrm{~ms}$ ) in agreement with experimental recordings (LAZZARO et al., 1998) and previous computational models (RUSU et al., 2014).

No difference in the latencies of I-waves was found while changing the coil direction from $0^{\circ}$ to $180^{\circ}$ (Figure 26, for a network without background activity), in disagreement with epidural recording studies showing earlier I-wave latencies for PA current direction when compared to AP direction (SAKAI et al., 1997). This lack of difference in I-wave latencies suggests that the architecture of the network in the present model is too simple (when compared with, e.g., a proposed canonical microcircuit for the cortex (DOUGLAS; MARTIN; WHITTERIDGE, 1989)) to capture the neuroanatomical factors involved in the sensibility of the motor-related brain tissue to current direction (such as chains of interneurons or association fibers (ZIEMANN, 2020)). However, an increase in the amplitude of the two later I-waves was observed in the response with the coil at $180^{\circ}$ direction.

\subsubsection{Membrane potential of neuronal compartments}

For a network with no external Poisson spike trains (stimulation intensity $400 \mathrm{~A} / \mu \mathrm{s}$ ), L2/3 neurons were activated with different latencies, with latency being shorter for greater stimulation intensities (i.e., L2/3 neurons were all activated in a progressively smaller time window). A single TMS pulse activated L2/3 neurons, with the L5 neuron firing even after L2/3 stopped firing (Figure 24A). A matrix with membrane potential of all compartments of a L2/3 neuron over time (Figure 24B) shows that the neuron activated only once, due to TMS pulse, eventually activating all of its axonal compartments; this happened for all L2/3 neurons of the network. The fact that the L5 neuron continued firing after pulse can be explained by the effect of synaptic currents in its dendritic tree (Figure 25).

L5 neurons showed, in general, a period of time (in Figure 23, of approximately 6.25 $\mathrm{ms}$ ) of suppressed activity after its initial spikes after the $400 \mathrm{~A} / \mu \mathrm{s}$ pulse (Figure 23). For higher stimulus intensities (e.g., $1200 \mathrm{~A} / \mu \mathrm{s}$ ), this low or null activity period reached durations up to $18 \mathrm{~ms}$; this duration is close to the cortical silent period (CSP) recorded in experimental studies (of around $23 \mathrm{~ms}$ ). This can be explained by $\mathrm{GABA}_{B}$ playing a role in CSP, as shown in previous computational studies (MOEZZI et al., 2018). 
Figure 22 - Simulated epidural recording, showing oscillations (I-waves) after a single pulse of TMS (with intensity $400 \mathrm{~A} / \mu \mathrm{s}$ and at coil orientation $180^{\circ}$ ) over the feedforward network under influence of background activity (i.e., Poisson spikes). TMS pulse was applied at $55 \mathrm{~ms}$ (indicated by red vertical line). Note that pulse was applied while the signal was rising due to ongoing rhythms on L5 neurons. Top-right corner: Real epidural response to TMS pulse of human motor cortex; adapted from Lazzaro et al. 1998 (LAZZARO et al., 1998) (RUSU et al., 2014).

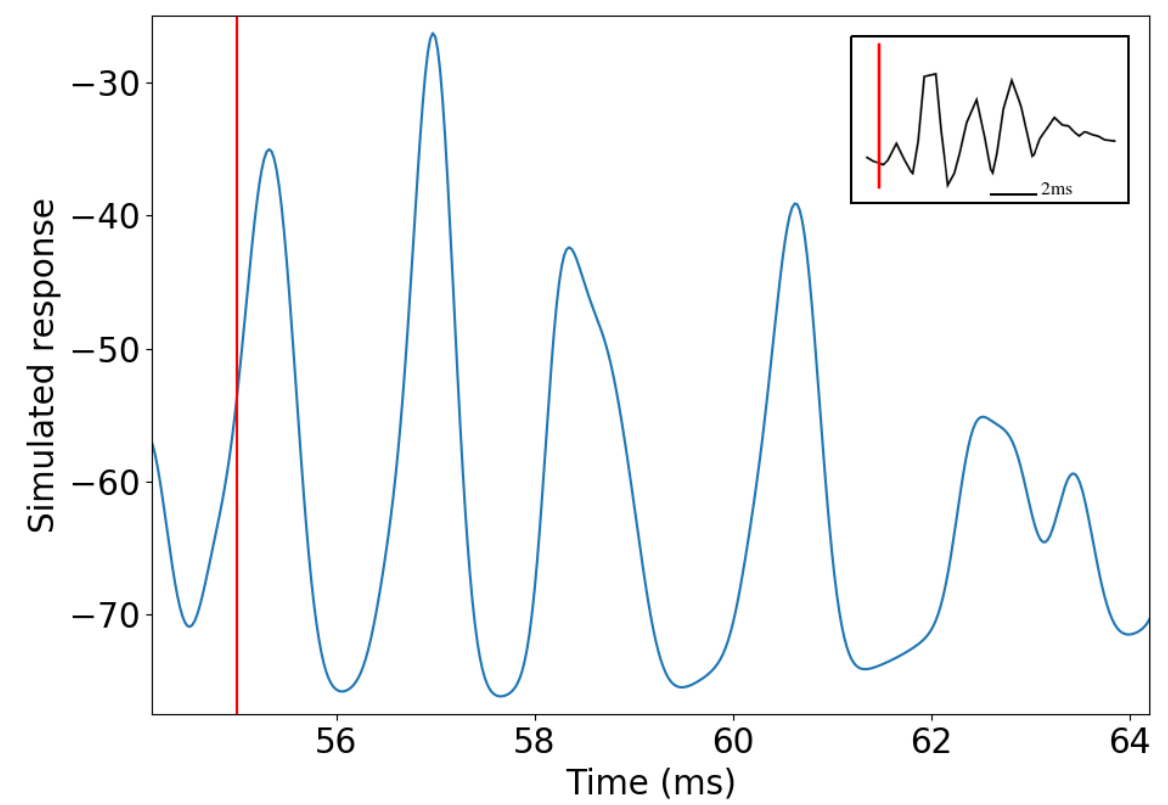

Figure 23 - Example of output of axon of a L5 neuron, at coil orientation $180^{\circ}$. Vertical axis indicates membrane potential $(\mathrm{mV})$; horizontal axis indicates time steps (with 100 time steps being $2.5 \mathrm{~ms}$ ). Vertical red line indicates time of 400 $\mathrm{A} / \mu \mathrm{s}$ TMS pulse (at $1.875 \mathrm{~ms}$ ). Note the 4 spikes (i.e., action potentials) after the pulse, with the fourth having larger latency, followed by approximately $6.25 \mathrm{~ms}$ of no activity.

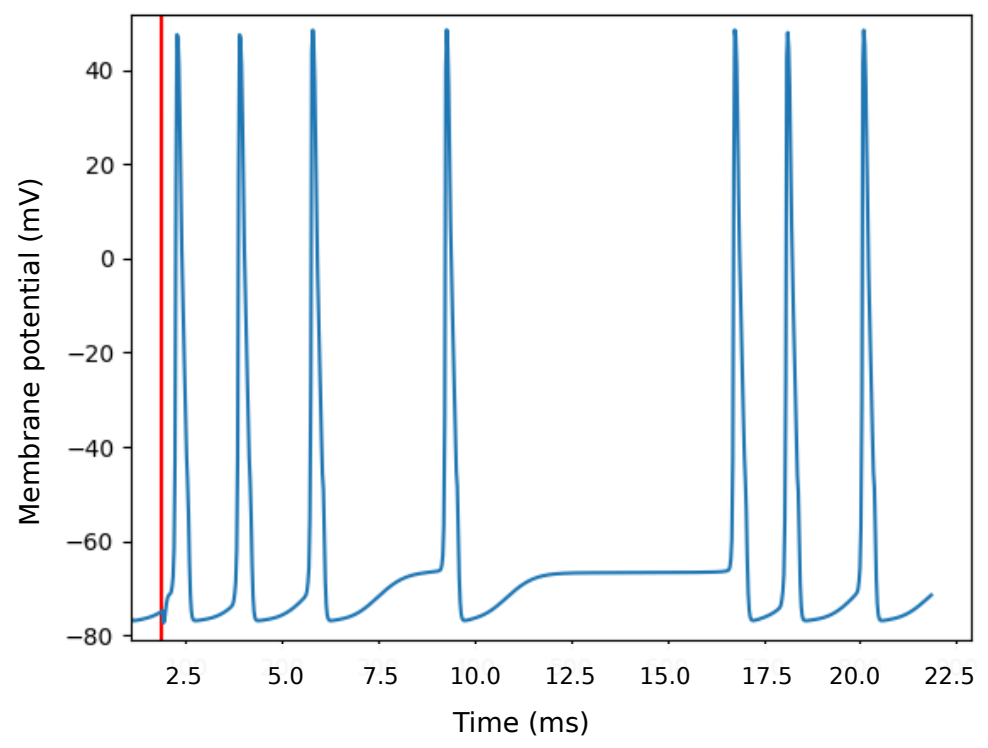


Figure 24 - Output of network with no Poisson spike trains over L2/3 neurons. 400A/ $\mu \mathrm{s}$, $180^{\circ}$ TMS pulse is applied $5 \mathrm{~ms}$ after beginning of simulation, with neurons assumed to be at rest. (A) Raster plot showing spikes of the 150 neurons; L5 neuron corresponds to the topmost group of spikes, with 6 spikes for the shown time period. Shown spikes correspond to axon activation, and not soma activation; for L5 neurons, they show activation of axon initial segment, and for L23 neurons, activation of the axon terminal that projects to L5 neuron. Horizontal axis indicates time, ranging from $0 \mathrm{~ms}$ to $10 \mathrm{~ms}$; vertical axis indicates neuron index in the network. (B) Membrane potential matrix for one L2/3 neuron, visualized in pseudocolor (color bar ranging from dark blue to yellow). Vertical axis indicates each compartment, with number being its index (axonal compartments have indices ranging from near 400 to 1395); horizontal axis indicates time (in $\mathrm{ms}$ ).
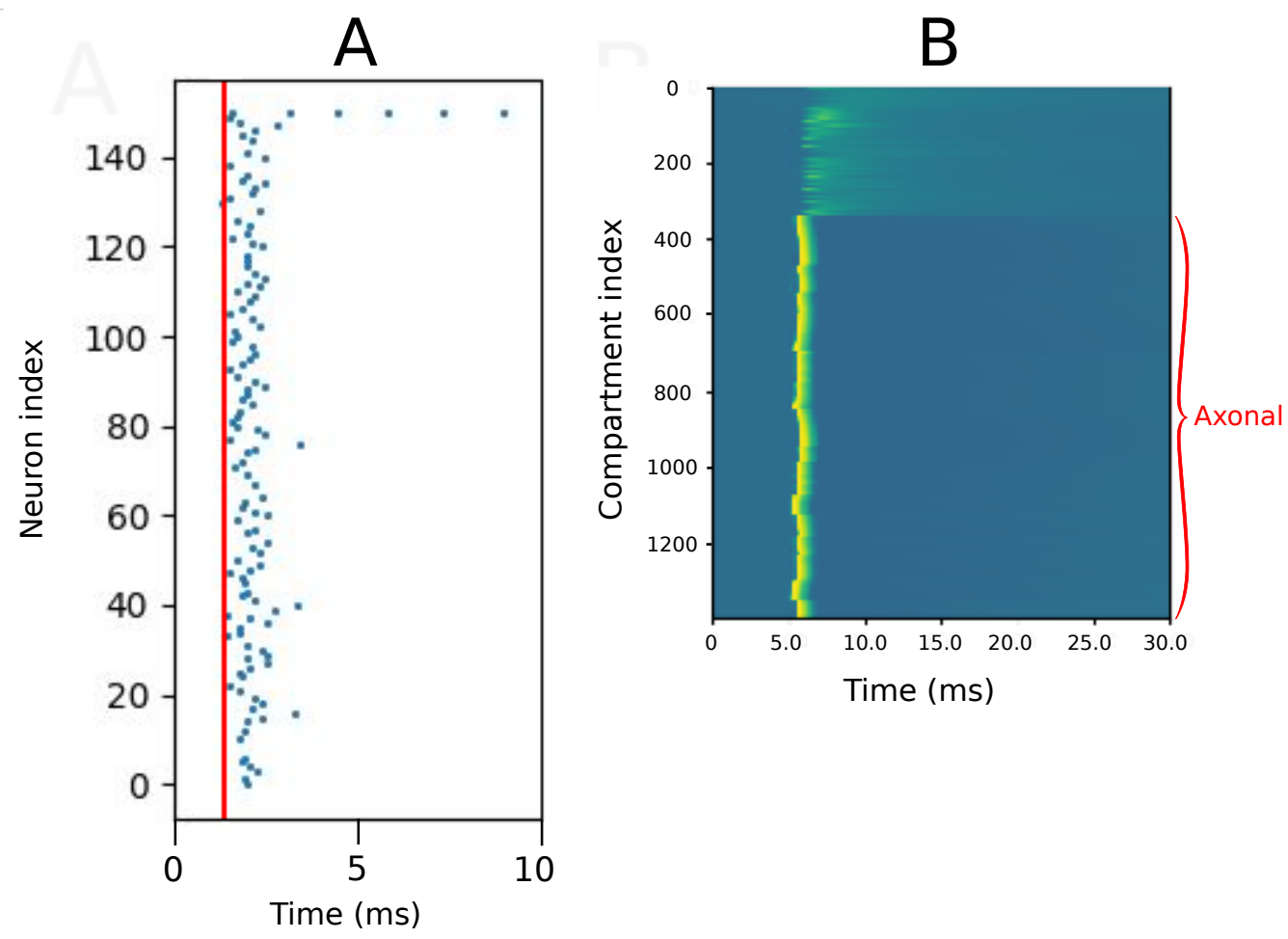
Figure 25 - Membrane potential matrix for L5 neuron in network with no Poisson spike trains over L2/3 neurons (same simulation as Figure 24). Horizontal axis indicates time (in ms); vertical axis indicates compartments of the neuron, with number being index. Crop shows membrane potential at dendritic compartments; note the depolarization sustained along time in many compartments.

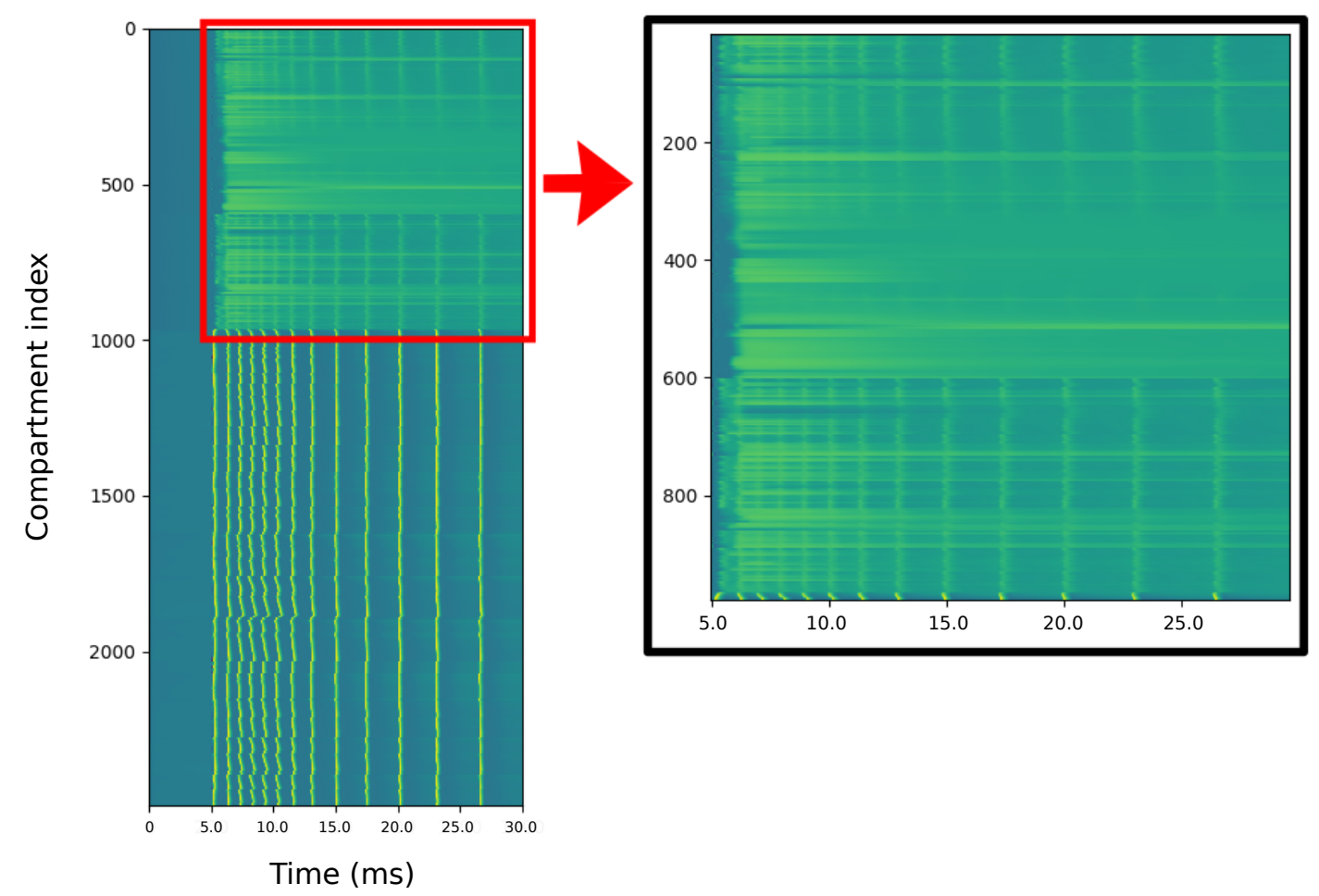

Figure 26 - Simulated epidural response for two different coil orientations: $0^{\circ}$ (perpendicular to central sulcus, PA direction) and $180^{\circ}$. Intensity of TMS pulse was $400 \mathrm{~A} / \mu$ s for both directions, with the network being assumed as being initially at rest and under no influence of background activity throughout the simulation.
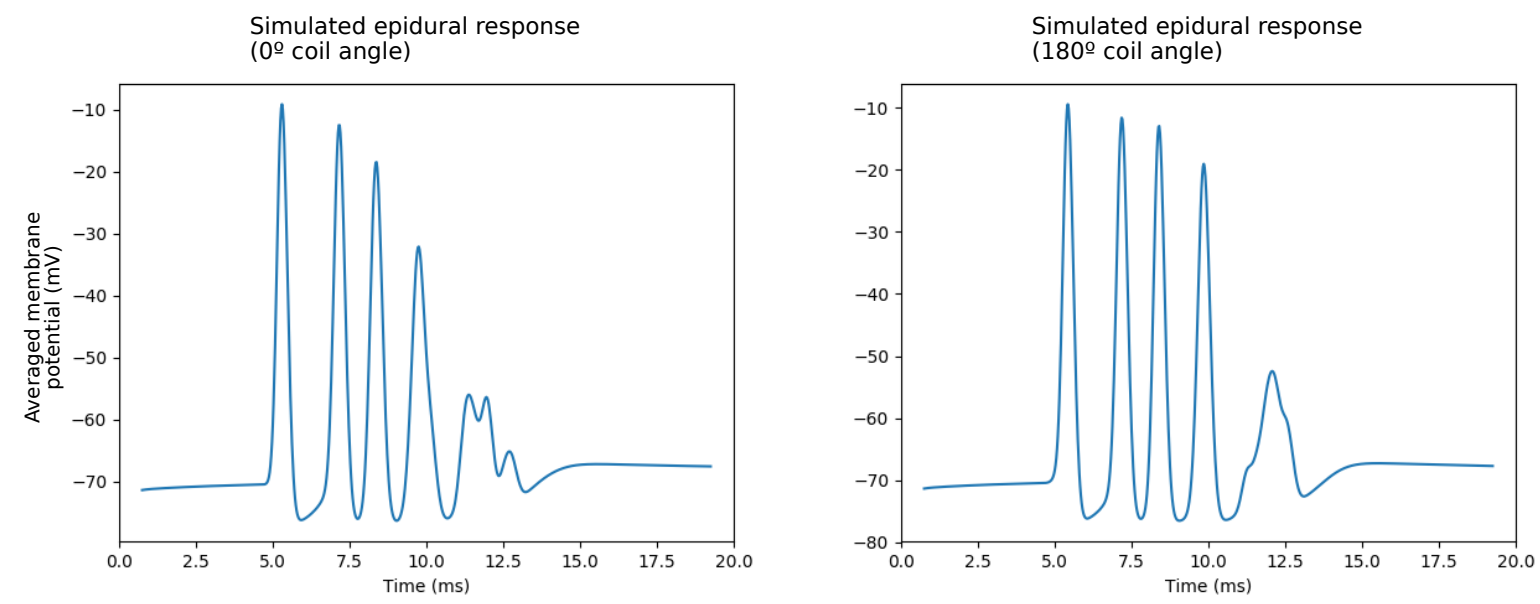


\section{Discussion}

\subsection{Synaptically isolated neurons under TMS pulse}

In accordance with analytical neurostimulation models (ROTH, 1994) and experimental studies (NAGARAJAN; DURAND, 1992), axon bendings, terminals and branchings (i.e., morphological discontinuities) were the sites of neuronal morphology with lowest excitation threshold.

The stimulated axon terminals presented a directional preference of being aligned with the applied electric field (which was assumed to be spatially uniform), although this preference was not perfect. This conclusion also agrees with analytical models, which predict that axon terminals aligned in the same direction of the applied uniform electric field are depolarized, while terminals aligned in the opposite direction of the field are hyperpolarized (ROTH, 1994) (PLONSEY; ALTMAN, 1988).

For L2/3 neurons, the lowest excitation thresholds were achieved with PA stimulation, with coil perpendicular to central sulcus $\left(0^{\circ}\right)$. The means of the excitation thresholds of all neurons of both layers, calculated at each coil orientation, were also lowest with the coil being perpendicular to central sulcus.

At 6 out of 8 simulated coil orientations, L5 neurons had a lower mean threshold when compared to L2/3 neurons. Due to their complex axonal arborization, which presents numerous sites with low excitation threshold, the cortical neurons simulated in the present study were stimulated by both tangential and radial electric field components, and, consequently, the magnitude of the applied electric field was a better predictor of excitation thresholds than the component of the electric field orthogonal to the cortical surface. This suggests that neurons in the gyral crown are more likely to be excited than neurons in the wall of the sulcus, since they are subjected to greater electric field magnitudes during TMS. These conclusions agree with recent computational studies (ABERRA et al., 2020). 


\subsection{Cortical motor network under TMS pulse}

The simulated epidural response showed oscillations with amplitude and duration similar to real recorded responses. This was achieved more parsimoniously by previous computational studies which did not include L2/3 neuron morphologies (RUSU et al., 2014), but the presence of such morphologies in the current results and the measured axonal activation show that such responses are also coherent with transsynaptic activation.

Within the network model, in all sampled L2/3 neurons, the TMS pulse generated action potentials at multiple sites of the axonal arbor with their propagation to all compartments occuring within $1.25 \mathrm{~ms}$ (Figure 24). This suggests that the TMS pulse either directly activates synaptic projections to the L5 neuron (due to activation of axon terminals) or activates them with a low latency, instead of causing the cell body to activate directly.

For the specific stimulation intensity of Figure 24, L2/3 neurons did not activate all immediately; latency for activation of the projection to L5 neuron differed for each L2/3 neuron (considering that the spikes in the raster plot show activation of the randomly chosen axon terminal that projected to the L5 neuron, and not the activation of the soma of the L2/3 neuron). Therefore, in addition with the role of the L5 neuron dendritic tree in producing latency in epidural waves - suggested in computational studies (RUSU et al., 2014) -, latency of action potential propagation in axonal arbors of L2/3 neurons also seem to play a role in latencies of I1-waves - given that, for greater stimulation intensities, neurons tended to activate in a more synchronized manner in the simulated network. This lower latency for greater stimulation intensities seem to be caused by activation of more sites in axonal arbor, which subsequently elevates the probability of the axon terminal projecting to the L5 neuron being activated in a small period of time. This possibly explains different latencies of I-waves for different coil orientations if the individual cortical curvature is considered, along with the different regions of gyri and sulci where total electric field magnitude is highest for each coil orientation. In this reasoning, neurons higher in the gyrus and closest to the coil would tend to have lower latencies of activation of their projections to L5 neurons, since they have lower thresholds at that specific coil position and orientation, being activated at multiple sites in the axonal arbor; in this case, cortical geometry could contribute to lower latencies in epidural waves if the distribution of total induced electric field varies spatially when compared with other coil orientations (ABERRA et al., 2020).

With respect to the network without external Poisson spikes, some sites in the dendritic tree of the L5 neuron kept an elevated membrane potential during the time period of simulation $(30 \mathrm{~ms})$, causing periodic action potentials to propagate down the dendritic tree and eventually cause all axon compartments to fire, and then generating the several action potentials seen in the axon of L5 neuron during the remaining $30 \mathrm{~ms}$ period of 
simulation (Figures 24 and 25). Considering that, during the time of simulation, L2/3 neurons fire only once (after application of TMS pulse), an explanation for the elevated membrane potential in sites of the dendritic tree is the resulting slow excitation caused by NMDA synapses. Since NMDA synapses have a time constant of $2.0 \mathrm{~ms}\left(\tau_{1}\right)$ and $27 \mathrm{~ms}$ $\left(\tau_{2}\right)$, inhibition caused by $G A B A_{B}$ synapses are too slow ( $\tau_{1}$ of $\left.45 \mathrm{~ms}\right)$ to counteract in the simulated time range of $30 \mathrm{~ms}$, whereas $G A B A_{A}$ is too fast $\left(\tau_{1}\right.$ of $0.3, \tau_{2}$ of 2.5$)$, acting in the first few milliseconds after activation of L2/3 neurons. Therefore, NMDA-activated currents, which have fast rise time and slow decay time, can explain the several action potentials seen in the axon of the L5 neuron in the period of $30 \mathrm{~ms}$ after TMS pulse.

\subsection{Conclusions}

The present computational model combined individual neuroanatomy and neuronal morphology into a motor cortex neuronal network, captured properties of experimental recordings in agreement with previous computational works, and offered explanations to poorly understood mechanisms of activation. Thus, it offers a framework for continued modeling studies that helps to guide the optimized and personalized use of TMS and related brain stimulation techniques. 



\section{References}

ABERRA, A. S.; PETERCHEV, A. V.; GRILL, W. M. Biophysically realistic neuron models for simulation of cortical stimulation. Journal of Neural Engineering, IOP Publishing, v. 15, n. 6, p. 066023, oct 2018. <https://doi.org/10.1088\%2F1741-2552\% 2Faadbb1>.

ABERRA, A. S. et al. Simulation of transcranial magnetic stimulation in head model with morphologically-realistic cortical neurons. Brain Stimulation, v. 13, n. 1, p. 175

- 189, 2020. ISSN 1935-861X. <http://www.sciencedirect.com/science/article/pii/ S1935861X19304097>.

ANGEVINE, J. B. et al. Principles of Neuroanatomy. [S.l.: s.n.], 1981. ISBN 9780195028850 .

APPUKUTTAN, S.; BRAIN, K. L.; MANCHANDA, R. Modeling extracellular fields for a three-dimensional network of cells using NEURON. Journal of Neuroscience Methods, Elsevier BV, v. 290, p. 27-38, out. 2017. <https://doi.org/10.1016/j.jneumeth.2017.07. $005>$.

BARKER, A.; JALINOUS, R.; FREESTON, I. Non-invasive magnetic stimulation of human motor cortex. The Lancet, Elsevier BV, v. 325, n. 8437, p. 1106-1107, maio 1985. <https://doi.org/10.1016/s0140-6736(85)92413-4>.

BARKER, A. T.; FREESTON, I. Transcranial magnetic stimulation. Scholarpedia, v. 2, n. 10, p. 2936, 2007. Revision \#137270.

BEAUliEU, C.; COLONNIER, M. A laminar analysis of the number of roundasymmetrical and flat-symmetrical synapses on spines, dendritic trunks, and cell bodies in area 17 of the cat. The Journal of Comparative Neurology, Wiley, v. 231, n. 2, p. 180-189, jan. 1985. <https://doi.org/10.1002/cne.902310206>.

BETTS, J. G. et al. Anatomy and Physiology. Houston, Texas: OpenStax, 2013. Book URL: <https://openstax.org/books/anatomy-and-physiology/pages/1-introduction>. Section URL: <https://openstax.org/books/anatomy-and-physiology/pages/ 12-2-nervous-tissue $>$.

BIKSON, M.; DMOCHOWSKI, J.; RAHMAN, A. The "quasi-uniform" assumption in animal and computational models of non-invasive electrical stimulation. Brain Stimulation, Elsevier BV, v. 6, n. 4, p. 704-705, jul. 2013. < https://doi.org/10.1016/j. brs.2012.11.005>.

BLAUSEN. Medical gallery of Blausen Medical 2014. WikiJournal of Medicine, n. 2, p. 10, 2014. ISSN 2002-4436. Available at: <https://en.wikiversity.org/ 
wiki/WikiJournal_of_Medicine/Medical_gallery_of_Blausen_Medical_2014>or $<$ https://commons.wikimedia.org/wiki/File:Blausen_0101_Brain_LateralView.png > . Accessed: June 15, 2020.

BOSSETTI, C. A.; BIRDNO, M. J.; GRILL, W. M. Analysis of the quasistatic approximation for calculating potentials generated by neural stimulation. Journal of Neural Engineering, IOP Publishing, v. 5, n. 1, p. 44-53, dez. 2007. $<$ https://doi.org/10.1088/1741-2560/5/1/005>.

CARNEVALE, N. T. The NEURON Book. [S.l.]: Cambridge University Press, 2006. <https://www.xarg.org/ref/a/0521843219/>. ISBN 9780521843218.

CHAKRABORTY, D. et al. Neuromodulation of axon terminals. Cerebral Cortex, Oxford University Press (OUP), v. 28, n. 8, p. 2786-2794, jun. 2017. <https: //doi.org/10.1093/cercor/bhx158>.

CONFORTO, A. B. et al. Impact of coil position and electrophysiological monitoring on determination of motor thresholds to transcranial magnetic stimulation. Clinical Neurophysiology, v. 115, n. 4, p. 812 - 819, 2004. ISSN 1388-2457. <http://www.sciencedirect.com/science/article/pii/S1388245703004218>.

CORTHOUT, E.; BARKER, A.; COWEY, A. Transcranial magnetic stimulation. Experimental Brain Research, Springer Science and Business Media LLC, v. 141, n. 1, p. 128-132, nov. 2001. <https://doi.org/10.1007/s002210100860>.

DAVILA-PÉREZ, P. et al. The effects of waveform and current direction on the efficacy and test-retest reliability of transcranial magnetic stimulation. Neuroscience, Elsevier BV, v. 393, p. 97-109, nov. 2018. <https://doi.org/10.1016/j.neuroscience.2018.09.044>.

DAY, B. L. et al. Electric and magnetic stimulation of human motor cortex: surface EMG and single motor unit responses. The Journal of Physiology, Wiley, v. 412, n. 1, p. 449-473, maio 1989. <https://doi.org/10.1113/jphysiol.1989.sp017626>.

DOUGLAS, R. J.; MARTIN, K. A.; WHITTERIDGE, D. A canonical microcircuit for neocortex. Neural Computation, MIT Press - Journals, v. 1, n. 4, p. 480-488, dez. 1989. $<$ https://doi.org/10.1162/neco.1989.1.4.480>.

ELDAIEF, M.; PRESS, D.; PASCUAL-LEONE, A. Transcranial magnetic stimulation in neurology a review of established and prospective applications. Neurology. Clinical practice, v. 3, p. 519-526, 122013.

EPSTEIN, C. M. et al. Localizing the site of magnetic brain stimulation in humans. Neurology, Wolters Kluwer Health, Inc. on behalf of the American Academy of Neurology, v. 40, n. 4, p. 666-666, 1990. ISSN 0028-3878. <https: //n.neurology.org/content/40/4/666>.

ESSER, S. K.; HILL, S. L.; TONONI, G. Modeling the Effects of Transcranial Magnetic Stimulation on Cortical Circuits. Journal of Neurophysiology, v. 94, n. 1, p. 622-639, jul. 2005. ISSN 0022-3077, 1522-1598. <https://www.physiology.org/doi/10.1152/jn.01230. $2004>$.

FOX, P. et al. Column-based model of electric field excitation of cerebral cortex. Human brain mapping, v. 22, p. 1-14, 052004. 
GOODWIN, B. D.; BUTSON, C. R. Subject-specific multiscale modeling to investigate effects of transcranial magnetic stimulation. Neuromodulation: Technology at the Neural Interface, Wiley, v. 18, n. 8, p. 694-704, maio 2015. <https: //doi.org/10.1111/ner.12296>.

GRATIY, S. L. et al. BioNet: A python interface to NEURON for modeling large-scale networks. PLOS ONE, Public Library of Science (PLoS), v. 13, n. 8, p. e0201630, ago. 2018. <https://doi.org/10.1371/journal.pone.0201630>.

GRUET, M. et al. Effect of different approaches to target force on transcranial magnetic stimulation responses. Muscle \& Nerve, Wiley, v. 48, n. 3, p. 430-432, jul. 2013. $<$ https://doi.org/10.1002/mus.23786>.

HAGEN, E. et al. LFPy - multimodal modeling of extracellular neuronal recordings in Python. [S.1.], 2019. <http://biorxiv.org/lookup/doi/10.1101/620286>.

HALLETT, M. Transcranial magnetic stimulation and the human brain. Nature, Springer Science and Business Media LLC, v. 406, n. 6792, p. 147-150, jul. 2000. $<$ https://doi.org/10.1038/35018000>.

HALLETT, M. Transcranial magnetic stimulation: A primer. Neuron, Elsevier BV, v. 55, n. 2, p. 187-199, jul. 2007. <https://doi.org/10.1016/j.neuron.2007.06.026>.

HALlETT, M.; CHOKROVERTY, S. (Ed.). Magnetic stimulation in clinical neurophysiology. 2nd ed. ed. Philadelphia, Pa: Elsevier Butterworth-Heinemann, 2005. ISBN 9780750673730.

HINES, M. NEURON and Python. Frontiers in Neuroinformatics, Frontiers Media SA, v. 3, 2009. <https://doi.org/10.3389/neuro.11.001.2009>.

HINES, M. L.; CARNEVALE, N. T. The NEURON simulation environment. Neural Computation, MIT Press - Journals, v. 9, n. 6, p. 1179-1209, ago. 1997. $<$ https://doi.org/10.1162/neco.1997.9.6.1179>.

HINES, M. L.; CARNEVALE, N. T. Neuron: A tool for neuroscientists. The Neuroscientist, v. 7, n. 2, p. 123-135, 2001. PMID: 11496923. <https://doi.org/10.1177/ $107385840100700207>$.

HOBBIE, R. K. Intermediate Physics for Medicine and Biology. [S.l.]: Springer, 2015. <https://www.xarg.org/ref/a/3319126814/>. ISBN 3319126814.

HORVATH, J. C. et al. Transcranial magnetic stimulation: a historical evaluation and future prognosis of therapeutically relevant ethical concerns. Journal of Medical Ethics, BMJ, v. 37, n. 3, p. 137-143, nov. 2010. < https://doi.org/10.1136/jme.2010.039966>.

HUNTER, J. D. Matplotlib: A 2d graphics environment. Computing in Science 86 Engineering, IEEE COMPUTER SOC, v. 9, n. 3, p. 90-95, 2007.

JESUS, D. R. de et al. Determining optimal rTMS parameters through changes in cortical inhibition. Clinical Neurophysiology, Elsevier BV, v. 125, n. 4, p. 755-762, abr. 2014. <https://doi.org/10.1016/j.clinph.2013.09.011>. 
JOUCLA, S.; YVERT, B. Modeling extracellular electrical neural stimulation: From basic understanding to MEA-based applications. Journal of Physiology-Paris, Elsevier BV, v. 106, n. 3-4, p. 146-158, maio 2012. < https://doi.org/10.1016/j.jphysparis.2011. $10.003>$.

KAMMER, T. et al. Motor thresholds in humans: a transcranial magnetic stimulation study comparing different pulse waveforms, current directions and stimulator types. Clinical Neurophysiology, Elsevier BV, v. 112, n. 2, p. 250-258, fev. 2001. <https://doi.org/10.1016/s1388-2457(00)00513-7>.

KANDEL, E. R. Principles of Neural Science, Fifth Edition (Principles of Neural Science (Kandel)). [S.l.]: McGraw-Hill Education / Medical, 2012. < https: //www.xarg.org/ref/a/0071390111/>. ISBN 9780071390118.

KANEKO, T. Local connections of excitatory neurons in motor-associated cortical areas of the rat. Frontiers in Neural Circuits, Frontiers Media SA, v. 7, 2013. $<$ https://doi.org/10.3389/fncir.2013.00075>.

KRIEG, T. D. et al. Computational and experimental analysis of TMS-induced electric field vectors critical to neuronal activation. Journal of Neural Engineering, IOP Publishing, v. 12, n. 4, p. 046014, jun. 2015. < https://doi.org/10.1088/1741-2560/12/4/ 046014>.

LAZZARO, V.; ZIEMANN, U.; LEMON, R. State of the art: Physiology of transcranial motor cortex stimulation. Brain stimulation, v. 1, p. 345-62, 102008.

LAZZARO, V. D. et al. The effect on corticospinal volleys of reversing the direction of current induced in the motor cortex by transcranial magnetic stimulation. Experimental Brain Research, Springer Science and Business Media LLC, v. 138, n. 2, p. 268-273, maio 2001. <https://doi.org/10.1007/s002210100722>.

LAZZARO, V. D. et al. Effects of voluntary contraction on descending volleys evoked by transcranial stimulation in conscious humans. The Journal of Physiology, Wiley, v. 508, n. 2, p. 625-633, abr. 1998. <https://doi.org/10.1111/j.1469-7793.1998.625bq.x>.

LINDÉN, H. et al. LFPy: a tool for biophysical simulation of extracellular potentials generated by detailed model neurons. Frontiers in Neuroinformatics, v. 7, 2014. ISSN 1662-5196. <http://journal.frontiersin.org/article/10.3389/fninf.2013.00041/abstract>.

MARKRAM, H. Microcircuitry of the neocortex. In: Handbook of Brain Microcircuits. [S.1.]: Oxford University Press, 2010. p. 22-30. <https://doi.org/10.1093/med/ 9780195389883.003.0003>.

MARKRAM, H. et al. Reconstruction and simulation of neocortical microcircuitry. Cell, Elsevier BV, v. 163, n. 2, p. 456-492, out. 2015. <https://doi.org/10.1016/j.cell.2015.09. $029>$.

MERTON, P. A.; MORTON, H. B. Stimulation of the cerebral cortex in the intact human subject. Nature, Springer Science and Business Media LLC, v. 285, n. 5762, p. 227-227, maio 1980. <https://doi.org/10.1038/285227a0>.

MOEZZI, B. et al. Simulation of electromyographic recordings following transcranial magnetic stimulation. Journal of Neurophysiology, v. 120, n. 5, p. 2532-2541, 2018. PMID: 29975165. <https://doi.org/10.1152/jn.00626.2017>. 
MUELLER, J. K. et al. Simultaneous transcranial magnetic stimulation and single-neuron recording in alert non-human primates. Nature Neuroscience, Springer Science and Business Media LLC, v. 17, n. 8, p. 1130-1136, jun. 2014. $<$ https://doi.org/10.1038/nn.3751>.

NAGARAJAN, S. S.; DURAND, D. Determination of excitation sites during magnetic stimulation of nerve fibers. In: 1992 14th Annual International Conference of the IEEE Engineering in Medicine and Biology Society. [S.l.: s.n.], 1992. v. 4, p. 1426-1427. ISSN null.

NEGGERS, S. F. et al. Chapter 10 - understanding the biophysical effects of transcranial magnetic stimulation on brain tissue: The bridge between brain stimulation and cognition. In: BESTMANN, S. (Ed.). Computational Neurostimulation. [S.l.]: Elsevier, 2015, (Progress in Brain Research, v. 222). p. 229 - 259. < http: //www.sciencedirect.com/science/article/pii/S0079612315001065>.

NIEBUR, E. Neuronal cable theory. Scholarpedia, v. 3, n. 5, p. 2674, 2008. Revision \#190845.

NOWAK, L. G.; BULLIER, J. Axons, but not cell bodies, are activated by electrical stimulation in cortical gray matter. Experimental Brain Research, Springer Science and Business Media LLC, v. 118, n. 4, p. 489-500, fev. 1998. $<$ https://doi.org/10.1007/s002210050305>.

OPITZ, A. et al. How the brain tissue shapes the electric field induced by transcranial magnetic stimulation. NeuroImage, Academic Press Inc., v. 58, n. 3, p. 849-859, 102011. ISSN 1053-8119.

PASHUT, T. et al. Mechanisms of magnetic stimulation of central nervous system neurons. PLoS Computational Biology, Public Library of Science (PLoS), v. 7, n. 3, p. e1002022, mar. 2011. <https://doi.org/10.1371/journal.pcbi.1002022>.

PLONSEY, R.; ALTMAN, K. Electrical stimulation of excitable cells - a model approach. Proceedings of the IEEE, v. 76, p. 1122 - 1129, 101988.

PLONSEY, R.; HEPPNER, D. B. Considerations of quasi-stationarity in electrophysiological systems. The Bulletin of Mathematical Biophysics, Springer Science and Business Media LLC, v. 29, n. 4, p. 657-664, dez. 1967. <https://doi.org/10.1007/bf02476917>.

PYTHON-VTK library page at the PyPI (Python Package Index). 2020. < https: //pypi.org/project/vtk/>. Accessed: 2020-06-01.

QUIQUEMPOIX, M. et al. Layer 2/3 pyramidal neurons control the gain of cortical output. Cell Reports, v. 24, n. 11, p. 2799 - 2807.e4, 2018. ISSN 2211-1247. <http://www.sciencedirect.com/science/article/pii/S2211124718313093>.

RATTAY, F. Analysis of models for external stimulation of axons. IEEE Transactions on Biomedical Engineering, Institute of Electrical and Electronics Engineers (IEEE), BME-33, n. 10, p. 974-977, out. 1986. <https://doi.org/10.1109/tbme.1986.325670>.

ROSSINI, P. et al. Non-invasive electrical and magnetic stimulation of the brain, spinal cord, roots and peripheral nerves: Basic principles and procedures for routine clinical and research application. an updated report from an i.f.c.n. committee. 
Clinical Neurophysiology, Elsevier BV, v. 126, n. 6, p. 1071-1107, jun. 2015. $<$ https://doi.org/10.1016/j.clinph.2015.02.001>.

ROTH, B. J. Mechanisms for electrical stimulation of excitable tissue. Critical reviews in biomedical engineering, v. 22 3-4, p. 253-305, 1994.

RUOHONEN, J. Basic physics and design of transcranial magnetic stimulation devices and coils. In: . [S.l.: s.n.], 2005. p. 17-30. ISBN 9780750673730.

RUSU, C. V. et al. A model of tms-induced i-waves in motor cortex. Brain Stimulation, v. 7, n. 3, p. 401 - 414, 2014. ISSN 1935-861X. < http://www.sciencedirect.com/science/ article/pii/S1935861X14001077>.

SAKAI, K. et al. Preferential activation of different i waves by transcranial magnetic stimulation with a figure-of-eight-shaped coil. Experimental Brain Research, Springer Science and Business Media LLC, v. 113, n. 1, p. 24-32, jan. 1997. $<$ https://doi.org/10.1007/bf02454139>.

SALVADOR, R. et al. Determining which mechanisms lead to activation in the motor cortex: A modeling study of transcranial magnetic stimulation using realistic stimulus waveforms and sulcal geometry. Clinical Neurophysiology, v. 122, n. 4, p. 748 - 758, 2011. ISSN 1388-2457. < http://www.sciencedirect.com/science/article/pii/ S1388245710007091>.

SCHAWORONKOW, N.; TRIESCH, J. Ongoing brain rhythms shape i-wave properties in a computational model. bioRxiv, Cold Spring Harbor Laboratory, 2017. <https://www.biorxiv.org/content/early/2017/10/20/205450>.

SCHOMER, D. L. Niedermeyer's Electroencephalography: Basic Principles, Clinical Applications, and Related Fields. [S.l.]: LWW, 2010. <https://www.xarg.org/ref/a/ $0781789427 />$. ISBN 0781789427.

SCHROEDER, W. J.; MARTIN, K. W.; LORENSEN, W. E. The visualization toolkit: an object-oriented approach to 3D graphics ; [visualize data in 3D - medical, engineering or scientific ; build your own applications with $C++$, Tcl, Java or Python ; includes source codes for VTK (supports UNIX, Windows and Mac)]. 3. ed. ed. New York, NY: Kitware Inc, 2002. OCLC: 248865298. ISBN 9781930934078.

SEO, H. et al. A multi-scale computational model of the effects of tms on motor cortex [version 3; peer review: 2 approved]. F1000Research, v. 5, n. 1945, 2017.

SKINNER, F. K. Conductance-based models. Scholarpedia, v. 1, n. 11, p. 1408, 2006. Revision \#125663.

SPRUSTON, N. Pyramidal neuron. Scholarpedia, v. 4, n. 5, p. 6130, 2009. Revision \#130430.

TERAO, Y.; UGAWA, Y. Basic mechanisms of TMS. Journal of Clinical Neurophysiology, Ovid Technologies (Wolters Kluwer Health), v. 19, n. 4, p. 322-343, ago. 2002. <https://doi.org/10.1097/00004691-200208000-00006>.

TERAO, Y. et al. Predominant activation of i1-waves from the leg motor area by transcranial magnetic stimulation. Brain Research, v. 859, n. 1, p. 137 - 146, 2000. ISSN 0006-8993. <http://www.sciencedirect.com/science/article/pii/S0006899300019752>. 
THICKBROOM, G.; SAMMUT, R.; MASTAGLIA, F. Magnetic stimulation mapping of motor cortex: factors contributing to map area. Electroencephalography and Clinical Neurophysiology/Electromyography and Motor Control, v. 109, n. 2, p. 79 - 84, 1998. ISSN 0924-980X. <http://www.sciencedirect.com/science/article/pii/S0924980X9800006X>.

THIELSCHER, A.; ANTUNES, A.; SATURNINO, G. B. Field modeling for transcranial magnetic stimulation: A useful tool to understand the physiological effects of TMS? In: 2015 37th Annual International Conference of the IEEE Engineering in Medicine and Biology Society (EMBC). [S.1.]: IEEE, 2015. < https: //doi.org/10.1109/embc.2015.7318340>.

THIELSCHER, A.; OPITZ, A.; WINDHOFF, M. Impact of the gyral geometry on the electric field induced by transcranial magnetic stimulation. NeuroImage, v. 54, p. 234-43, 012011.

VIRTANEN, P. et al. SciPy 1.0: Fundamental Algorithms for Scientific Computing in Python. Nature Methods, v. 17, p. 261-272, 2020. <https://rdcu.be/b08Wh>.

WALT, S. van der; COLBERT, S. C.; VAROQUAUX, G. The NumPy array: A structure for efficient numerical computation. Computing in Science \& Engineering, Institute of Electrical and Electronics Engineers (IEEE), v. 13, n. 2, p. 22-30, mar. 2011. < https://doi.org/10.1109/mcse.2011.37>.

WANG, B.; GRILL, W. M.; PETERCHEV, A. V. Coupling magnetically induced electric fields to neurons: longitudinal and transverse activation. Cold Spring Harbor Laboratory, mar. 2018. <https://doi.org/10.1101/275073>.

WASSERMAN, E.; EPSTEIN, C. M.; ZIEMANN, U. (Ed.). The Oxford handbook of transcranial stimulation. Oxford ; New York: Oxford University Press, 2008. (Oxford handbooks series). ISBN 9780198568926.

WAXMAN, S. Clinical Neuroanatomy, 26th Edition. [S.1.]: McGraw-Hill Medical, 2009. <https://www.xarg.org/ref/a/0071603999/>. ISBN 0071603999.

WINDHOFF, M.; OPITZ, A.; THIELSCHER, A. Electric field calculations in brain stimulation based on finite elements: An optimized processing pipeline for the generation and usage of accurate individual head models. Human Brain Mapping, Wiley, v. 34, n. 4, p. 923-935, nov. 2011. < https://doi.org/10.1002/hbm.21479>.

WINDHOFF, M.; OPITZ, A.; THIELSCHER, A. Electric field calculations in brain stimulation based on finite elements: An optimized processing pipeline for the generation and usage of accurate individual head models. Human Brain Mapping, v. 34, n. 4, p. 923-935, 2013. <https://onlinelibrary.wiley.com/doi/abs/10.1002/hbm.21479>.

ZHOU, Q. PyMesh online documentation. 2020. < https://pymesh.readthedocs.io/en/ latest/>. Accessed: 2020-06-01.

ZIEMANN, U. Transcranial magnetic stimulation at the interface with other techniques: A powerful tool for studying the human cortex. The Neuroscientist, v. 17, n. 4, p. 368-381, 2011. PMID: 21311054. <https://doi.org/10.1177/1073858410390225>.

ZIEMANN, U. I-waves in motor cortex revisited. Experimental Brain Research, Springer Science and Business Media LLC, mar. 2020. < https://doi.org/10.1007/ s00221-020-05764-4>. 